\title{
Dense movement with embedded sparse action-type representations in the output layer of motor cortex
}

\author{
Stephen P. Currie ${ }^{1^{*}}$, Julian Ammer ${ }^{1^{*}}$, Brian Premchand ${ }^{1^{*}}$, Yufei $\mathrm{Wu}^{3}$, Constantinos \\ Eleftheriou $^{1,2}$, Aldo Faisal ${ }^{3,4,5}$, Matthias H. Hennig ${ }^{6}$ \& Ian Duguid ${ }^{1,2}$.
}

1. Centre for Discovery Brain Sciences / Patrick Wild Centre, Edinburgh Medical School: Biomedical Sciences, University of Edinburgh, Edinburgh, Scotland, EH8 9XD, UK.

2. Simons Initiative for the Developing Brain, Edinburgh Medical School: Biomedical Sciences, University of Edinburgh, Edinburgh, Scotland, EH8 9XD, UK.

3. Department of Bioengineering, Imperial College London, London, SW7 2AZ, UK.

4. Department of Computing, Imperial College London, London, SW7 2AZ, UK.

5. MRC London Institute of Medical Sciences, London, W12 0NN, UK.

6. Institute for Adaptive and Neural Computation, School of Informatics, The University of Edinburgh, Edinburgh EH8 9AB, UK.

For correspondence: Stephen.Currie@ed.ac.uk (SC); lan.Duguid@ed.ac.uk (ID)

*These authors contributed equally to this work 


\begin{abstract}
:
Motor cortex generates output necessary for the execution of a wide range of motor behaviours. Although neural representations of movement have been described throughout motor cortex, how population activity in output layers relates to the execution of distinct motor actions is less well explored. To address this, we imaged layer 5B population activity in mice performing a two-action forelimb task. We found most neurons convey a generalised movement signal, with action-type-specific signalling restricted to relatively small, spatially intermingled subpopulations of neurons. Deep layer population dynamics largely reflect dense, action-invariant signals that correlate with movement timing, while embedded sparse action-type representations reflect distinct forelimb actions. We suggest that sparse coding of action-type enhances the number of possible output configurations necessary for behavioural flexibility and the execution of a wide repertoire of behavioural actions.
\end{abstract}

\title{
Introduction:
}

Descending motor commands originating in deep layers of motor cortex propagate to subcortical, brainstem and spinal cord circuits to initiate a large repertoire of movements (Brecht et al., 2004; Cheney and Fetz, 1980; Esposito et al., 2014; Lawrence and Kuypers, 1968; Lemon, 2008; Miri et al., 2017; Omrani et al., 2017; Wang et al., 2017; Yakovenko and Drew, 2015). In primates and rodents, disrupting cortical output directly affects limb coordination and timing (Brochier et al., 1999; Brown and Teskey, 2014; Galiñanes et al., 2018; Guo et al., 2015; Lawrence and Kuypers, 1968; Morandell and Huber, 2017; Ueno et al., 2018), while stimulation evokes a range of complex motor actions (Ferrier, 1873; Graziano et al., 2002; Harrison et al., 2012; Hira et al., 2015; Li and Waters, 1991). The firing rates of individual neurons in motor cortex correlate with various aspects of limb movement such as joint angle, direction, and speed (Georgopoulos et al., 1982; Moran and Schwartz, 1999; Paninski et al., 2004; Thach, 1978), while population activity likely reflects multiplexed sensorimotor signals necessary for coordinating evolving movement trajectories (Ames et al., 2019; Churchland et al., 2012; Hatsopoulos et al., 2007; Kaufman et al., 2016; Sauerbrei et al., 2019). Functional maps of motor cortex have been generated for forelimb reach (Amirikian and Georgopoulos, 2003; Georgopoulos et al., 2007; Harrison et al., 2012; Hira et al., 2015; Wang et al., 2017), rhythmic movements (Dombeck et al., 2009; Hira et al., 2015) and object manipulation (Hira et al., 2013). Despite this, we still do not fully understand the extent to which distinct motor actions are represented in the output layers of motor cortex or how this information is spatiotemporally organised.

Recent advances in viral tools and optical imaging have enabled access to laminar-specific spatiotemporal dynamics of interconnected neuronal populations in rodent motor cortex (Park 
et al., 2019; Peters et al., 2014; Peters et al., 2017; Wang et al., 2017). During the execution of single forelimb actions, principal neurons in both superficial and deep layers display dense activity patterns that causally relate to the initiation and/or ongoing evolution of movements (Dacre et al., 2019; Estebanez et al., 2017; Hira et al., 2013; Isomura et al., 2009; Levy et al., 2020; Park et al., 2019; Sauerbrei et al., 2019; Wang et al., 2017). These reproducible, laminar-specific activity patterns emerge across motor learning and correlate with enhanced limb coordination (Laubach et al., 2000; Masamizu et al., 2014; Peters et al., 2014; Peters et al., 2017). But whether deep layer cortical activity patterns represent specific actions or a more generalised motor signal is still in debate. For example, mice performing skilled reaches with a single endpoint trajectory display dense motor cortex activity with $>70 \%$ of neurons encoding task-related movement (Sauerbrei et al., 2019), whereas multi-directional centre-out forelimb reaches appear to be encoded by sparse action-specific activity in superficial layers (Galiñanes et al., 2018). To address this issue, we sought to investigate how action representations are organised in one of the main output layers of primary motor cortex, layer $5 \mathrm{~B}$, since its output targets subcortical, brainstem and spinal cord circuits necessary for the selection and execution of motor actions (Esposito et al., 2014; Kita and Kita, 2012; Shepherd, 2013; Wang et al., 2017).

We performed deep-layer 2-photon calcium imaging in the caudal forelimb area (CFA) of mice trained to perform an alternating abduction / adduction lever task. By combining population imaging with single neuron / population-based classifiers and dimensionality reduction, we show that layer 5B neurons display dense movement but sparse action-type representations. Neurons conveying action-type-specific information displayed uncorrelated activity patterns that spanned the entire movement period and were spatially intermingled within forelimb motor cortical microcircuits. Our findings have important implications for understanding the functional organisation and coding of action-specific information in the output layers of rodent motor cortex.

\section{Results}

To explore different models of action representation (Figure 1A) (Dombeck et al., 2009; Galiñanes et al., 2018; Harrison et al., 2012; Hira et al., 2015; Sauerbrei et al., 2019), we first developed a cued linear abduction / adduction lever task for mice. The task design, incorporating two diametrically opposing actions (abduction - extension of the forelimb away from the body vs adduction - retraction of the limb towards the body), required mice to push or pull a horizontal lever $4 \mathrm{~mm}$ upon presentation of a $6 \mathrm{kHz}$ auditory cue (Figure 1B and C). By incorporating two opposing actions we aimed to maximise differences in forelimb biomechanics, muscle activation and neural activity patterns (Georgopoulos et al., 1982). Mice 
A
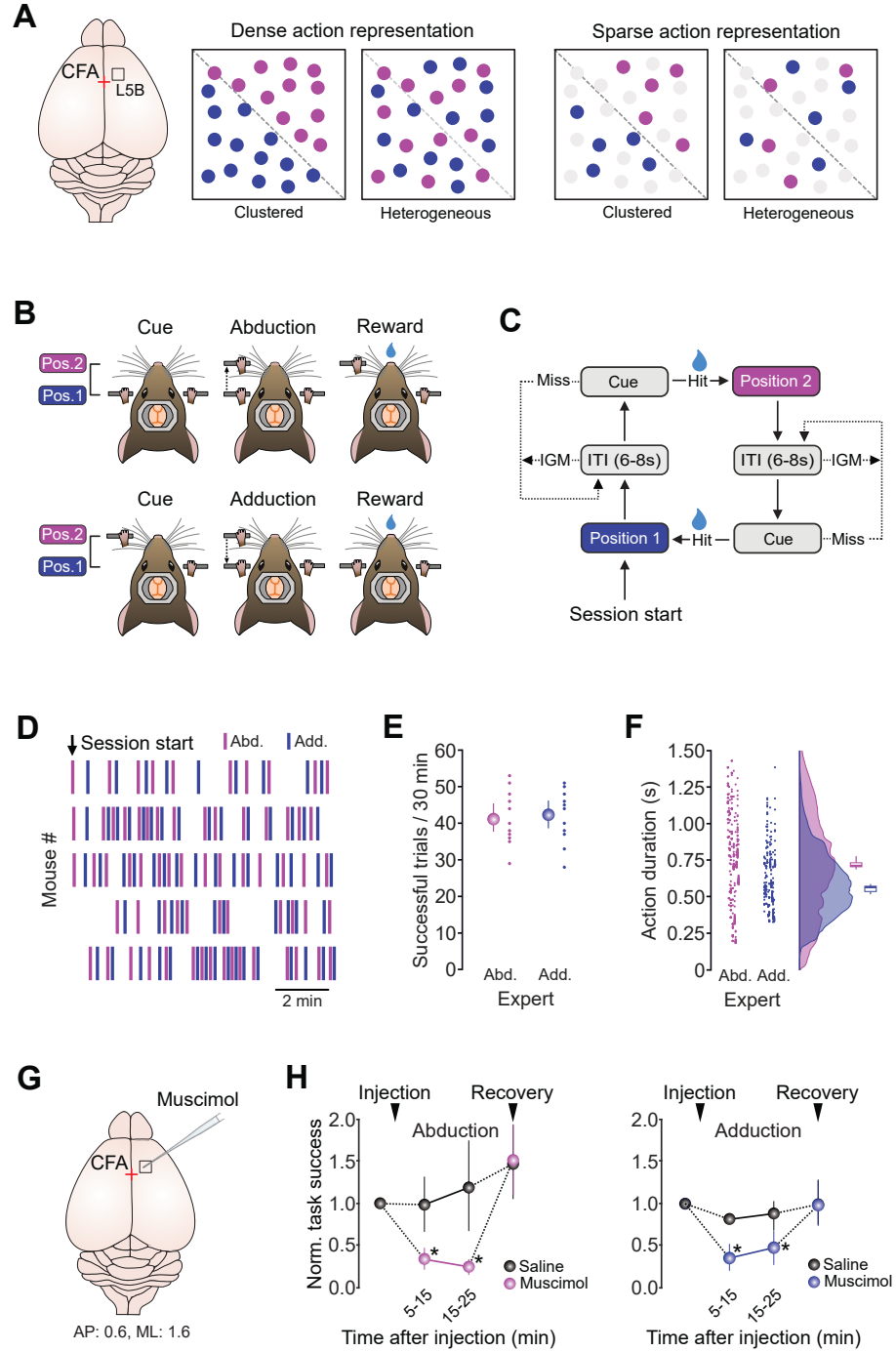

Figure 1 - Caudal forelimb area is necessary for cued abduction / adduction task execution.

(A) Models of layer 5B action-type representations in caudal forelimb motor cortex (CFA). (B) Cued alternating abduction / adduction task for head restrained mice. (C) Behavioural task structure: ITI, inter-trial interval; IGM, internally generated movement. (D) Behavioural task success in 5 expert mice during the first 10 minutes of training. Each row represents the behaviour of an individual mouse. Purple, successful abduction (Abd.) trial; blue, successful adduction (Add.) trial. (E) Average number of rewards received per 30 minute training session ( 12 mice). (F) Raincloud plot of action duration in expert mice. Box-and-whisker plots of bootstrapped estimates of the median action duration (whiskers represe task success for abduction (left; purple) and adduction (right, blue) trials as a function of time after muscimol injection. Coloured symbols represent changes in population means 2.7×10-2 (adduction), 2-way repeated measures ANOVA, with Bonferroni-Holm correction for multiple comparisons).

rapidly learned the task (mean $=12.8$ days, $95 \% \mathrm{Cl}[11.314 .2]$, all data, unless otherwise stated, are presented as mean, [bootstrapped 95\% confidence interval] and average data is given per mouse, $\mathrm{N}=12$ mice), performing sequences of abduction / adduction movements with reproducible across-session success but differences in kinematic trajectories, reflecting two independent actions (abduction - 41.3 trials / 30 min [37.5.0 45.2], median action duration $=713.5 \mathrm{~ms}, 95 \% \mathrm{Cl}[706.5,733.5]$; adduction -42.3 trials / $30 \mathrm{~min}$ [38.4 45.9], median action duration $=566 \mathrm{~ms} \mathrm{95 \%} \mathrm{Cl} \mathrm{[537.3,} \mathrm{573.0],} \mathrm{N} \mathrm{=} 12$ mice) (Figure 1D - F and Supplementary Video 1). To confirm motor cortical output was required for both actions, we focally injected the $\mathrm{GABA}_{\mathrm{A}}$ receptor agonist muscimol centred on the caudal forelimb area (Dacre et al., 2019; Schiemann et al., 2015). By applying muscimol during behavioural engagement we could assess the immediate effects of CFA inactivation 5-15 mins after drug injection (Figure 1G). Muscimol rapidly blocked initiation of both actions, reducing overall task success by $\sim 65 \%$, an 
effect that persisted for the duration of the session before recovering after 24 hours (5-15 mins, abduction - normalised task success $=0.34[0.220 .47], \mathrm{N}=6$ mice, $F(1,2)=2.25, P=$ $1.4 \times 10^{-2}$, two-way ANOVA; adduction - normalised task success $=0.35$ [0.20 0.53], $\mathrm{N}=6$ mice $\left.F(1,2)=1.62, P=3.2 \times 10^{-3}\right)$ (Figure $1 \mathrm{H}$ and Supplementary Video 2). Blocking cortical output resulted in either monoparesis of the contralateral forelimb (i.e. localised weakness without complete loss of function) or an inability to initiate learned movements, both of which affected successful task completion (Supplementary Video 2).

To examine how output from motor cortex relates to the execution of distinct motor actions, we imaged behaviour-related population activity in layer 5B of motor cortex, the upper boundary of which was identified by the presence of pyramidal tract neurons (boundary $\geq 500$ $\mu \mathrm{m}$ from the pial surface at the centre of CFA) (Schiemann et al., 2015) (Figure 2A and B and Supplementary Figure 1). A large proportion of layer 5B neurons displayed movement-related activity changes (468 / 653 neurons, $73.5 \%$ [64.7 81.8] per field-of-view (FOV) from 12 FOVs, $N=6$ mice; see Methods) the remainder being classified as non-responsive (147 / 653 neurons, 20.9 \% [12.8 29.1] per FOV) or 'reward phase' neurons (38 / 653 neurons, 5.7 \% [3.7 7.7] per FOV) (Figure $2 \mathrm{C}$ and $\mathrm{D}$ ). By separating abduction and adduction trials, we found that most layer 5B neurons displayed movement-related activity changes that were indistinguishable between actions (287 / 468 neurons, median $=59.8 \%$, interquartile range (IQR) [42.9 74.3], $\mathrm{N}=6$ mice), with only a small fraction of neurons distinguishing action type (termed action bias, abduction bias $-81 / 468$ neurons, median = 14.3 \%, IQR [12.7 28.6]; adduction bias - 100 / 468 neurons, median = 11.8 \%, IQR [8.2 27.7]) (Figure 2E and F). Neural responses displaying action bias were classified into six different types including both positive and negative changes in $\Delta \mathrm{F} / \mathrm{F}_{0}$, consistent with bidirectional action-specific tuning of neural activity (Georgopoulos et al., 1982). The majority of action bias neurons (76\%) showed significant changes in $\Delta F / F_{0}$ for both actions, while only $24 \%$ (43/181 neurons) displayed action selectivity (i.e. significant change in $\Delta F / F_{0}$ for one action, with no response for the opposing action) (Supplementary Figure 2A). In terms of spatial organisation, action bias neurons were found in all FOVs and were spatially intermingled with non-bias neurons (Figure $2 F$ and $G$ ). Although our task design required mice to execute actions from two different starting positions, action bias was in general not driven by postural differences (seen as differences in inter-trial baseline $\Delta F / F_{0}$ ) but rather reflected the type of movement being executed (Supplementary Figure 2B and $\mathrm{C}$ ). To challenge our physiology-based classification of action bias, we adopted an unbiased, data-driven approach using a Gaussian Naïve Bayes classifier to identify whether action type could be decoded from the activity of individual layer 5B neurons (Figure $2 \mathrm{H}$ and $\mathrm{I}$ ). We found that $\sim 70 \%$ of neurons that displayed action bias had decoding accuracy scores above chance $(122 / 181$ neurons, median $=67.3 \%$, IQR [42.6 
A
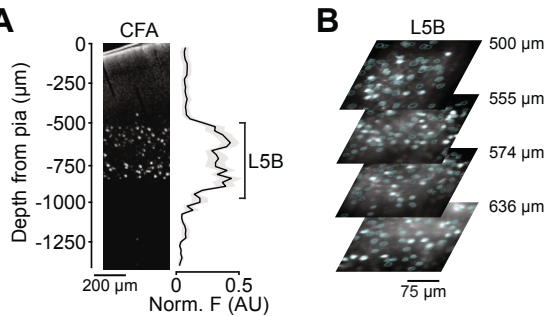

E
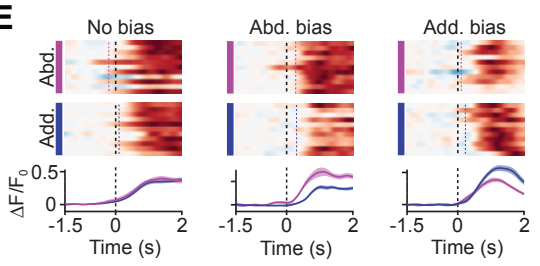

$\mathbf{F}$
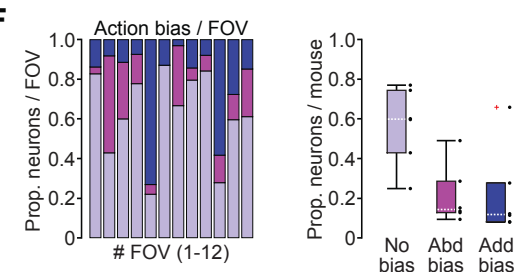

G
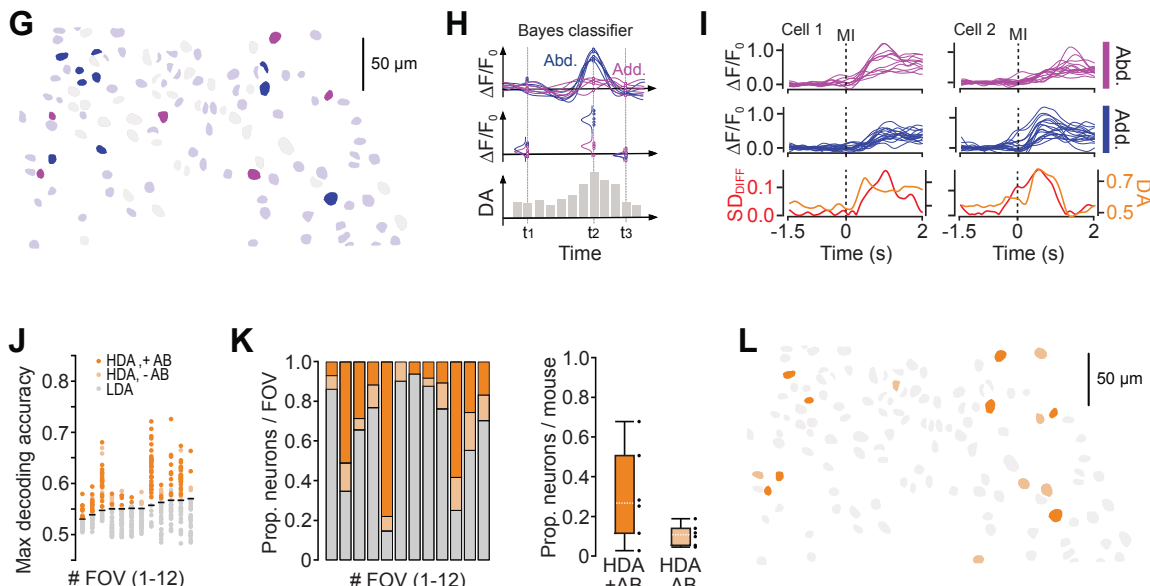

K
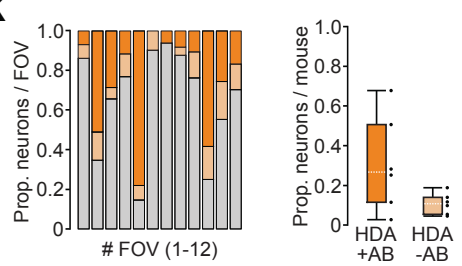

$\mathbf{L}$

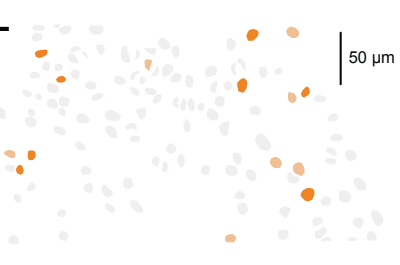

Figure 2. Dense movement with embedded sparse action-type representations in layer $5 \mathrm{~B}$

(A) Cortical depth profile of pyramidal tract (PT-type) neurons in caudal forelimb area (CFA): Left, RetroBead labelling of PT-type neurons following injection into the pons; Right, normalised fluorescence \pm s.e.m as a function of depth from the pia $(\mathrm{N}=3$ mice). Black line indicates the upper and lower boundary of layer $5 \mathrm{~B}$ across mice. (B) Representative 2-photon imaging fields-of-view ( $F O V s$ ) from layer $5 \mathrm{~B}$ in $\mathrm{CFA}\left(\mathrm{N}=4\right.$ mice). Cyan circles depict regions of interest. (C) $\Delta \mathrm{F} / \mathrm{F}_{0}$ traces from four example layer $5 \mathrm{~B}$ neurons during task execution (grey vertical bars). Black traces depict neurons with movement-related activity; grey trace depicts activity during the reward phase. (D) Proportion of neurons per FOV
that are non-responsive (white), movement-related (black) or display activity only during the reward phase (grey) $(n=12$ FOVs, $N=6$ mice). Black dots represent individual FOVs, that are non-responsive (white), movement-related (black) or display activity only during the reward phase (grey) ( $\mathrm{n}=12 \mathrm{FOVs}, \mathrm{N}=6$ mice). Black dots represent individual FOVs, bars represent mean and $95 \% \mathrm{Cl}$. (E) Three example movement-related layer $5 \mathrm{~B}$ neurons: Left, no action bias; Middle, abduction bias; Right, adduction bias. Top, raster showing normalised $\triangle F / F_{0}$ across successive abduction or adduction trials, Bottom, $\triangle F F$ of movement. Dotted lines represent median $\Delta F / F$ onsets. ( $F$ ) Proportion of action-biased neurons per FOV. Left, proportion of movement-related neurons with no action bias $\mathrm{N}=6$ mice). Black dots represent individual mice. Red cross marks identified outlier. (G) Example FOV showing neurons with abduction (purple) and adduction bias (blue). Violet, non-action bias neurons; grey, non-responsive or reward phase neurons. (H) Naïve Bayes classifier: Top, modelled $\Delta F / F_{0}$ during abduction (purple) and adduction (blue) trials. Middle, Gaussian distributions derived from trial samples (circles). Bottom, decoding accuracy (DA) across time. (I) Two example action-biased neurons: Left, abduction-biased; Right, adduction-biased. Top, smoothed $\Delta \mathrm{F} / \mathrm{F}_{0}$ on abduction (purple) and adduction (middle, blue) trials. Bottom, decoding accuracy (DA) (orange) and the absolute difference in standard deviation of $\triangle \mathrm{F} / \mathrm{F}_{0}$ on abduction and adduction trials $\left(\mathrm{SD}_{\text {DIFEF }}\right.$, red). Dashed lines represent onset of movement. (J) Maximum decoding accuracy during peri-movemen epoch. Circles represent individual neurons; black horizontal lines indicate significance threshold (see Methods). HDA, high decoding accuracy; LDA, low decoding accuracy; + AB, with action bias; $-\mathrm{AB}$, no action bias. (K) Left, proportion of neurons per FOV with high or low decoding accuracy. Right, box-and-whisker plots showing median, interquartile range
and range across mice ( $\mathrm{n}=486$ neurons from $12 \mathrm{FOV}, \mathrm{N}=6$ mice). Black dots represent individual mice. HDA, +AB (dark orange); HDA, -AB (light orange) and LDA (grey). (L) Example FOV showing high decoding accuracy neurons with (dark orange) or without (light orange) action bias.

79.3], $\mathrm{N}=6 \mathrm{mice}$ ) (Figure 2J), with a small minority of non-action bias neurons also representing action type. Consistent with our physiology-based classification, neurons with above chance decoding accuracy were found in the majority of FOVs, were spatially intermingled with other cell types and represented a small fraction of the total population of neurons with movement-related activity (124 / 468 neurons, median $=27.1 \%$, IQR [11.8 51.0], $\mathrm{N}=6$ mice) (Figure $2 \mathrm{~K}$ and $\mathrm{L}$ ). Together, our data suggest that most layer 5B neurons convey a generalised action-invariant motor signal, whereas a small fraction of neurons convey action-specific information. 
bioRxiv preprint doi: https://doi.org/10.1101/2020.10.27.357087; this version posted October 27, 2020. The copyright holder for this preprint (which was not certified by peer review) is the author/funder, who has granted bioRxiv a license to display the preprint in perpetuity. It is made available under aCC-BY 4.0 International license.

Given the high trial-to-trial variability in $\Delta \mathrm{F} / \mathrm{F}_{0}$ and resultant moderate decoding scores in individual neurons (see Figure 2l), we reasoned that population responses could provide a more robust movement-related signal that would enhance decoding of action type (Levy et al., 2020; Masamizu et al., 2014; Wei et al., 2019). By applying logistic regression (Figure 3A), population decoding was consistently more accurate when compared to decoding from single neurons (single cell median decoding accuracy $=0.61$, IQR $[0.580 .65]$; population median decoding accuracy $0.75,[0.630 .79], \mathrm{N}=6$ mice, $\mathrm{W}=1, \mathrm{Z}=-2.2, P=2.8 \times 10^{-2}$, Wilcoxon signed rank test) (Figure $3 \mathrm{~B}$ ). However, this increase was driven by a small proportion of neurons with high decoding accuracy. Removing the top $\sim 20 \%$ of neurons based on single

A

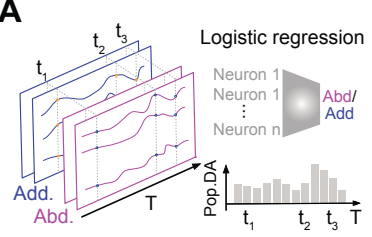

D

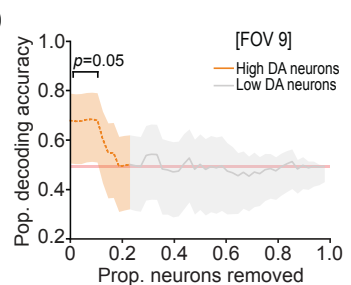

B

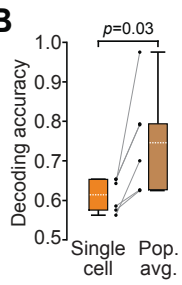

E

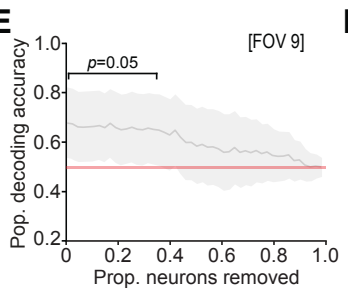

C

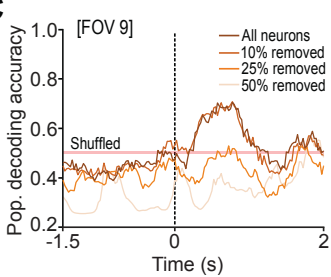

F

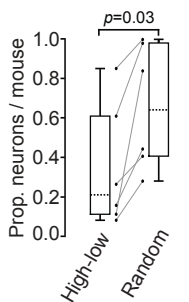

G
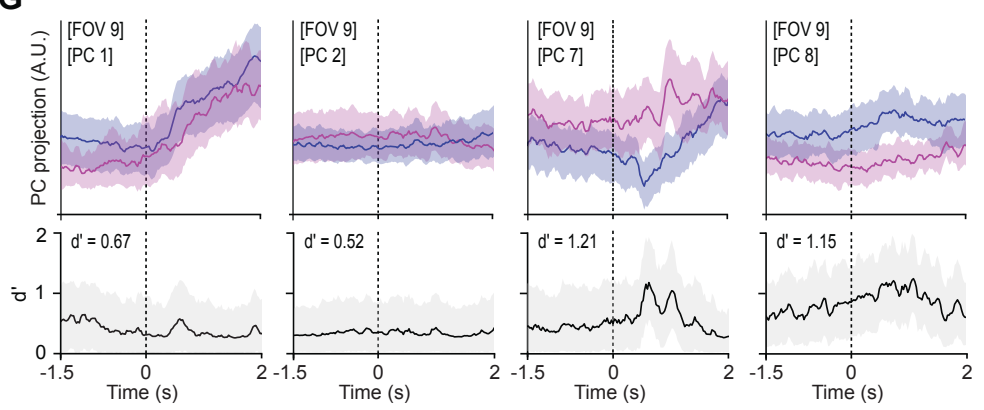

H

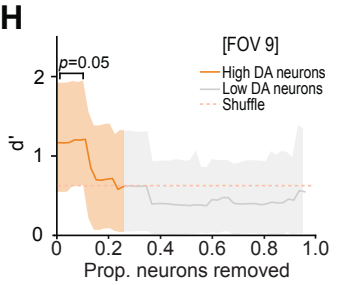

I
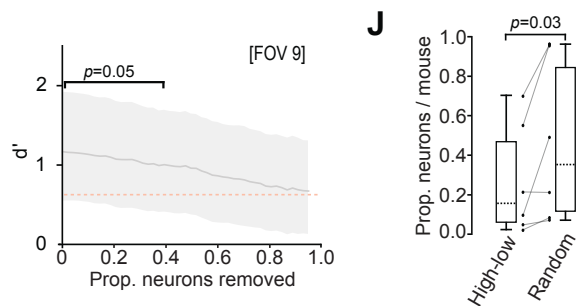

Figure 3. Population decoding relies on a small proportion of high decoding accuracy neurons.

(A) Population decoding of action-type. Trial-to-trial $\Delta F / F_{0}$ for all neurons in a field-of-view (FOV) were used to calculate the population decoding accuracy (DA) using logistic regression (see Methods). (B) Box-and-whisker plots showing the median, interquartile range and range of single cell and population $D A(n=12 \mathrm{FOV}, N=6$ mice, $W=1, Z=$ $-2.2, P=2.8 \times 10^{-2}$, Wilcoxon Signed-rank test). Black dots represent individual mice. Single cell DA accuracy (orange) were calculated using a Gaussian naïve Bayes classifier, population DA averages were calculated using logistic regression (brown). (C) Mean population DA for all neurons or after removal of 10-50\% neurons in order from high to low single cell decoding accuracy (Figure $2 \mathrm{~J}$ ). Red shaded area depicts the $95 \% \mathrm{Cl}$ based on shuffled data. Dashed line represents onset of movement. (D) Change in maximum
population decoding accuracy for an example FOV after the sequential removal of neurons in order from high (orange) to low (grey) single cell decoding accuracy (Figure $2 \mathrm{~J}$ ). Thick population decoding accuracy for an example FOV after the sequential removal of neurons in order from high (orange) to low (grey) single cell decoding accuracy (Figure $2 \mathrm{~J}$ ). Thick
line represents mean and $95 \% \mathrm{CI}$. Red shaded area depicts the $95 \% \mathrm{Cl}$ based on shuffled data. (E) Change in maximum population decoding accuracy for an example $\mathrm{FOV}$ after line represents mean and $95 \% \mathrm{Cl}$. Red shaded area depicts the $95 \% \mathrm{Cl}$ based on shuffled data. (E) Change in maximum population decoding accuracy for an example FOV after
the random removal of individual neurons. Thick line represents mean and $95 \% \mathrm{Cl}$. Red shaded area depicts the $95 \% \mathrm{Cl}$ based on shuffled data. (F) Box-and-whisker plots showing the median, interquartile range and range for ordered (high-to-low decoding accuracy) versus random removal of neurons $\left(n=12 \mathrm{FOVs}, \mathrm{N}=6\right.$ mice, $W=1, Z=-2.2, P=2.8 \times 10^{-2}$, Wilcoxon Signed-rank test). Black dots represent individual mice. (G) Top. Example trajectories over time of 4 principal components (PC) for abduction (purple) and adduction (blue) trials from an example FOV. Bottom, discrimination index (d') calculated from the corresponding PCs. Thick line represents mean and $95 \%$ Cl. Dashed lines represent movement onset. (H) Change in maximum d' for an example FOV after the sequential removal of neurons in order from high (orange) to low (grey) single cell decoding accuracy
(Figure 2J). Example is from PC 7 (Figure 3G) - the PC with the highest significant d' value in this FOV. Thick line represents mean and $95 \%$ Cl. Red dashed line depicts the 95\% $\mathrm{Cl}$ based on shuffled data. (I) Change in maximum d' for an example FOV after the random removal of individual neurons. Thick line represents mean and $95 \% \mathrm{Cl}$. Red dashed line depicts the $95 \% \mathrm{Cl}$ based on shuffled data. ( $\mathrm{J}$ ) Box-and-whisker plots showing the median, interquartile range and range for sequential (high-to-low decoding accuracy) versus random removal of neurons ( $N=6$ mice, $W=1, Z=-2.2, P=3.1 \times 10^{-2}$, Wilcoxon Signed-rank test). Black dots represent individual mice. 
cell decoding accuracy abolished action-type classification (median prop. removed $=0.21$, [0.11 0.61], $N=6$ mice) (Figure 3C-D and F), whereas, sequential removal of randomly selected neurons resulted in a significantly larger proportion of neurons having to be removed before decoding accuracy reduced to chance (median prop. removed $=0.64,[0.410 .98], \mathrm{N}=$ 6 mice, $W=1, Z=-2.2, P=2.8 \times 10^{-2}$, Wilcoxon signed rank test) (Figure $3 E$ and $F$ ). To further explore the underlying structure of layer $5 B$ population activity, we employed principal component analysis (Churchland et al., 2012; Churchland et al., 2010; Cunningham and Yu, 2014; Kaufman et al., 2014; Stopfer et al., 2003). For the leading 16 principal components of the population activity, we compared the difference between abduction and adduction trials, in order to compute a discrimination index (d') (Figure 3G and Supplementary Figure 3). Leading principal components tended to be more similar across actions, while action type was often better represented by higher components (Figure 3G). Despite correlating with population decoding scores, high d' values were not preferentially associated with the leading principle components of the population activity (Supplementary Figure 3), suggesting actiontype is not a dominant signal in the population response (Kaufman et al., 2016). We explored this further by comparing d' scores following sequential removal of individual neurons. Removing the top $\sim 15 \%$ of neurons based on single cell decoding accuracy abolished actiontype discrimination (median prop. removed $=0.15,[0.050 .47], \mathrm{N}=6$ mice) (Figure $3 \mathrm{H} \& \mathrm{~J}$ ), whereas, the random removal of neurons required a significantly larger proportion of the population to be removed before d' values reduced to chance (median prop. removed $=0.35$, [0.11 0.85], $N=6$ mice, $W=1, Z=-2.2, P=3.1 \times 10^{-2}$, Wilcoxon signed rank test) (Figure 3 I \& J). Together, these results indicate that while action-type can be decoded from population activity, this is dependent on a relatively small proportion of high decoding accuracy neurons that contribute a small proportion of the overall variance.

Functional clustering of neurons appears to be a common feature of population activity in motor cortex (Amirikian and Georgopoulos, 2003; Cheney et al., 1985; Dombeck et al., 2009; Georgopoulos et al., 2007; Harrison et al., 2012; Hira et al., 2013; Hira et al., 2015; Isomura et al., 2009; Jones and Wise, 1977; Komiyama et al., 2010; Wang et al., 2017). We examined the spatiotemporal organization of high decoding accuracy neurons and found that within each FOV the onset of $\Delta F / F_{0}$ changes were first observed $\sim 300$ ms prior to movement, consistent with a role in preparation / initiation (Dacre et al., 2019; Estebanez et al., 2017; Isomura et al., 2009; Li et al., 2015a), and tiled the movement period up to reward delivery ( 1-1.5 s; abduction - high decoding accuracy neurons median $\Delta \mathrm{F} / \mathrm{F}_{0}$ onset $=119 \mathrm{~ms}$, IQR [83.3 142.9], range [-875 1450]; adduction - $167 \mathrm{~ms}$, [95.2 177.4], -925 1350], N = 6 mice). However, neurons with different $\Delta F / F_{0}$ onsets appeared spatially heterogenous (Figure $4 A$ and $B$ ). To explore correlations in peri-movement activity patterns, we split neurons based on their 
A

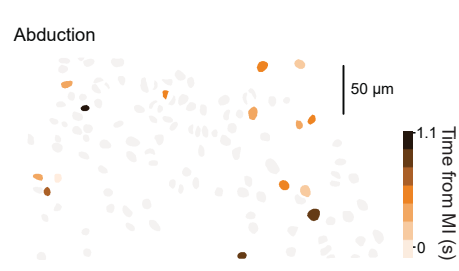

D

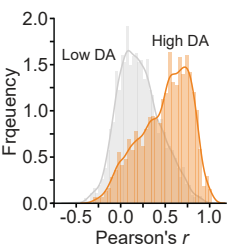

B

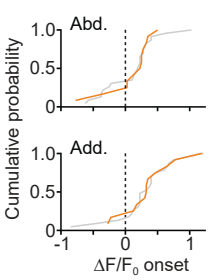

E

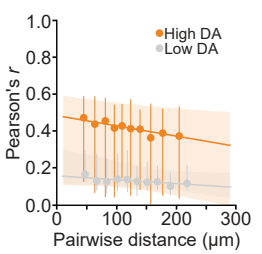

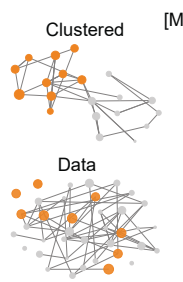

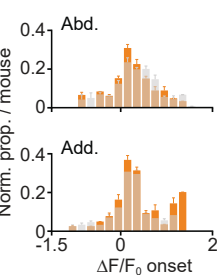

C
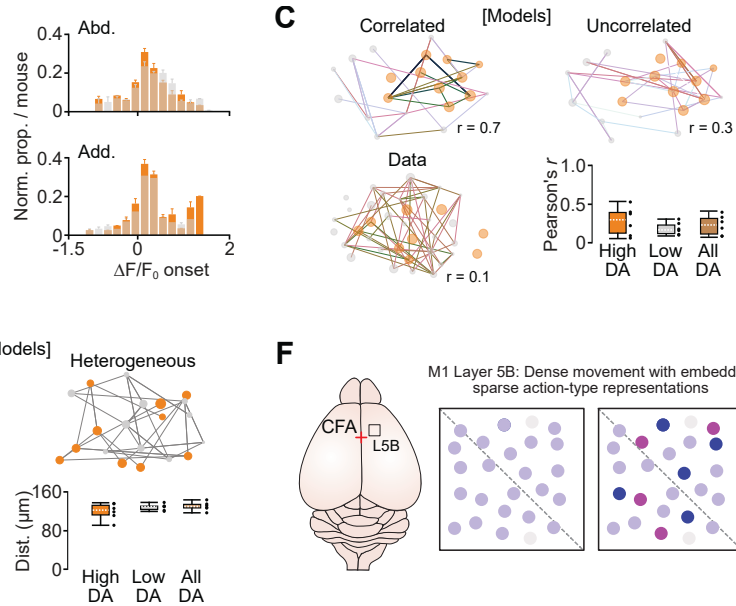

$\mathbf{F}$

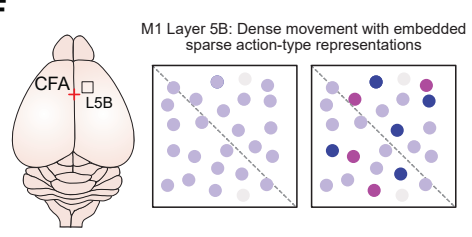

Figure 4. Heterogeneous spatiotemporal organisation of high decoding accuracy neurons.

(A) Example field-of-view (FOV) showing spatial distribution of $\Delta \mathrm{F} / \mathrm{F}_{\mathrm{o}}$ onsets for high decoding accuracy neurons during abduction trials. MI, movement initiation. Colours represent $200 \mathrm{~ms}$ bins tiling the peri-movement epoch: $-100 \mathrm{~ms}$ (light orange) to $+1100 \mathrm{~ms}$ (dark brown). (B) Left, cumulative probability plots of $\Delta F / F$ onsets for high decoding accuracy (HDA, orange) and low decoding accuracy neurons (LDA, grey) from the example FOV shown in (A). Right, histograms of $\triangle F / F_{0}$ onsets for HDA and LDA neurons during abduction (top) and adduction (bottom) (rals ( constructed from the pairwise activity correlations from a representative FOV; Bottom right, box-and-whisker plots showing the median, interquartile range and ranctional network coefficients across mice for HDA (orange), LDA (grey) and all (brown) neurons. Black dots represent correlation values for individual mice. Line colour (light to dark) and width coefficients across mice for HDA (orange), LDA (grey) and all (brown) neurons. Black dots represent correlation values for individual mice. Line colour (light to dark) and width accuracy $(n=468$ neurons from 12 FOVs, $N=6$ mice). (D) Left, distributions of pairwise correlation coefficient for HDA (orange) and LDA (grey) neurons; Right, median pairwise correlation coefficient with $95 \% \mathrm{Cl}$ as a function of pairwise distance for HDA (orange) and LDA (grey) neurons. Horizontal lines denote linear regression model fit, with shaded regions representing the bootstrapped $95 \% \mathrm{Cl}(\mathrm{P}=0.19,95 \% \mathrm{Cl}[-0.0030 .014], \mathrm{n}=11954$ observations, $\mathrm{N}=6$ mice). (E) Modelled functional network depicting clustered (top left) and spatially heterogeneous (top right) HDA neurons. Each node, represented by a circle, corresponds to a neuron, while the connections represent the pairwise distances between neurons; Bottom left, functional network constructed from the pairwise distances between neurons in a representative FOV; Bottom right, box-and-whisker plots showing the median, interquartile range and range of median pairwise distances across mice for HDA (orange), LDA (grey) and all (brown) neurons $(n=468 \mathrm{neurons}$ from $12 \mathrm{FOVs}$, $N=6$
mice). Black dots represent pairwise distances for individual mice. $(F)$. Revised model of layer $5 \mathrm{~B}$ movement representations in caudal forelimb motor cortex (CFA). Coloured circles represent non-responsive (grey), movement-responsive (violet), abduction biased (purple) and adduction biased (blue) neurons.

decoding accuracy scores (high, low and all) and compared pairwise activity during abduction or adduction trials observing only weak correlations within and across groups (Figure $4 \mathrm{C}$ and Supplementary Figure 4). Next, we compared the activities of pairs of neurons as a function of their pairwise distance. Neurons separated by less anatomical distance did not show correlated $\Delta F / F_{0}$ changes, suggesting an absence of functional clustering (Figure 4D and $E$ ). Confidence intervals provide a lower bound indication of cluster size such that, if present, spatial clusters based on decoding accuracy would have to be less than $\sim 50 \mu \mathrm{m}$. Thus, layer 5B neurons that convey action-type information appear to be temporally and spatially heterogeneous.

\section{Discussion}

Volitional forelimb movements are thought to be represented by relatively dense activity patterns in both superficial and deep layers of motor cortex (Dacre et al., 2019; Estebanez et al., 2017; Hira et al., 2013; Isomura et al., 2009; Levy et al., 2020; Park et al., 2019; Sauerbrei et al., 2019; Wang et al., 2017), but whether these patterns represent specific actions (Galiñanes et al., 2018) or a more generalised motor signal (Kaufman et al., 2016) remains unresolved. By combining population imaging with single neuron / population-based classifiers and dimensionality reduction in mice, we find that most layer 5B neurons display actioninvariant signalling, while action-specific representations are restricted to sparse, spatially heterogeneous subpopulations of neurons. Our findings provide constraints on models of 
spatiotemporal movement representations (Figure 4F), developing our understanding of how action-specific information is organized in the output layers of motor cortex.

In rodents, volitional forelimb movements such as reach-to-grasp (Estebanez et al., 2017; Galiñanes et al., 2018; Guo et al., 2015; Levy et al., 2020; Sauerbrei et al., 2019; Wang et al., 2017) or pulling / pushing a grasped lever (Dacre et al., 2019; Hira et al., 2013; Isomura et al., 2009; Miri et al., 2017; Morandell and Huber, 2017; Park et al., 2019) have been associated with widespread, bidirectional neuronal modulation in both superficial and deep layers of sensorimotor cortex, driven by long-range inputs from motor thalamus (Dacre et al., 2019; Sauerbrei et al., 2019; Tanaka et al., 2018). Both excitatory and inhibitory neurons display dense task-related activity which emerges across learning and correlates with enhanced limb coordination (Hwang et al., 2019; Laubach et al., 2000; Masamizu et al., 2014; Peters et al., 2014). Disrupting this activity affects limb kinematics suggesting dense cortical activity may be a common cortical motif representing specific motor actions (Gao et al., 2018; Guo et al., 2015; Li et al., 2015b; Sauerbrei et al., 2019). Our data challenge this view, in that most layer 5B neurons display similar activity patterns irrespective of action-type, indicative of a more generalised motor signal that conveys information necessary for movement, but not for specific actions. Action-invariant signals likely provide a generic timing signal, triggering statedependent switching from stable neural dynamics during rest towards oscillatory dynamics that underpin movement initiation and execution (Churchland et al., 2010; Kaufman et al., 2014; Kaufman et al., 2016; Kurtzer et al., 2005) and similar to condition-invariant population transitions observed in recurrent neural networks trained to recapitulate complex muscle patterns in reaching primates (Sussillo et al., 2015). Since the cerebellar thalamocortical pathway conveys timing signals, which when disrupted affects movement initiation (Dacre et al., 2019; Sauerbrei et al., 2019; Thach, 1978), action-invariant signalling in cortex could reflect a generic broadcast signal from the cerebellum signalling the intention to move, irrespective of action type. This broadcast signal likely combines with long-range actionspecific inputs targeted to specific subpopulations of neurons to generate embedded sparse action-type representations. In addition, action-invariant signalling may also provide online input to downstream subcortical controllers to ensure maintained limb position in the absence of motor commands necessary for executing volitional movements (Albert et al., 2020; Kaufman et al., 2016). It will be interesting in the future to apply methods to selectively disrupt action-dependent and action-invariant signalling to explore their contribution to postural control and limb kinematics across multiple distinct actions.

Within layer 5B, we found that decoding of action-type was restricted to a subpopulation of neurons which could reflect routing of action information through specific output channels 
(Biane et al., 2016; Economo et al., 2018; Oswald et al., 2013; Park et al., 2019; Ueno et al., 2018; Wang et al., 2011; Wang et al., 2017). Similar activity patterns have also been observed in layer 5 projection neurons in anterior lateral motor cortex - a possible homologue of premotor cortex in primates - where distributed preparatory activity in intratelencephalic neurons converts to motor commands in pyramidal tract neurons for directional licking (Chen et al., 2017; Li et al., 2015a; Svoboda and Li, 2018). Although we did not identify the projection targets of high decoding accuracy neurons in this study, dense movement representations with sparse activation of deep layer projection neurons may be a generalised organising principle for channelling action-specific information during the planning and execution of volitional movements. Such activity patterns could be directly inherited from powerful top-down inputs from upper layers of motor cortex (Galiñanes et al., 2018; Weiler et al., 2008), driven by direct or indirect ascending input from the motor thalamus (Dacre et al., 2019; Gaidica et al., 2018; Hooks et al., 2013; Sauerbrei et al., 2019) or shaped by convergent input from multiple cortical and subcortical pathways conveying action-specific information (Hooks et al., 2013; Hooks et al., 2018). The spatiotemporal heterogeneity of action-specific activity in layer $5 \mathrm{~B}$ differs from models that emphasise spatial clustering in primates (Amirikian and Georgopoulos, 2003; Cheney et al., 1985; Georgopoulos et al., 2007; Jones and Wise, 1977) and superficial layers of rodent motor cortex (Dombeck et al., 2009; Hira et al., 2013; Hira et al., 2015; Komiyama et al., 2010). The reason for these differences remains unclear but may reflect laminar-specific differences in functional connectivity that facilitate routing of information through distinct cortical output channels (Biane et al., 2016; Economo et al., 2018; Oswald et al., 2013; Park et al., 2019; Ueno et al., 2018; Wang et al., 2011; Wang et al., 2017) or task-specific differences in movement representations that relate to voluntary actions (e.g. licking, object manipulation or reaching) (Galiñanes et al., 2018; Isomura et al., 2009; Li et al., 2015a). Functional anatomical mapping of input-output transformations in identified layer 5B projection neurons will be a necessary next step towards building a mechanistic understanding of how action-specific information propagates through deep layers of motor cortex.

What is the computational advantage of sparse action representations as a coding strategy? In deep layers of cortex, intratelencephalic neurons constitute a major source of input to the dorsolateral striatum controlling action selection and vigour (Panigrahi et al., 2015; Park et al., 2020; Shepherd, 2013; Yttri and Dudman, 2016), while pyramidal tract neurons project to brainstem (Esposito et al., 2014) and spinal cord circuits involved in movement execution (Basista and Yoshida, 2020; Cheney and Fetz, 1980; Economo et al., 2018; Ueno et al., 2018; Wang et al., 2017). Flexible, sparse recruitment, via long-range inputs (Hooks et al., 2013) and hierarchical input-output connectivity (Kiritani et al., 2012; Shepherd, 2013; Weiler et al., 2008) of intratelencephalic and pyramidal tract neurons conveying action-specific information 
would greatly enhance the number of possible output configurations necessary to realise a large repertoire of kinematic representations. Our work suggests that deep-layer sparse cortical representations embedded within dense action-invariant signalling may be an organising principle that could ensure behavioural flexibility across motor actions. Further work exploring how sparse cortical codes influence downstream motor areas will be essential for understanding how cortex controls the planning and execution of distinct motor actions.

\section{References}

Albert, S.T., Hadjiosif, A.M., Jang, J., Zimnik, A.J., Soteropoulos, D.S., Baker, S.N., Churchland, M.M., Krakauer, J.W., and Shadmehr, R. (2020). Postural control of arm and fingers through integration of movement commands. Elife 9, e52507.

Ames, K.C., Ryu, S.I., and Shenoy, K.V. (2019). Simultaneous motor preparation and execution in a last-moment reach correction task. Nat Commun 10, 2718.

Amirikian, B., and Georgopoulos, A.P. (2003). Modular organization of directionally tuned cells in the motor cortex: is there a short-range order? Proc Natl Acad Sci U S A 100, 12474-12479.

Basista, M., and Yoshida, Y. (2020). Corticospinal Pathways and Interactions Underpinning Dexterous Forelimb Movement of the Rodent. Neuroscience.

Biane, J.S., Takashima, Y., Scanziani, M., Conner, J.M., and Tuszynski, M.H. (2016). Thalamocortical Projections onto Behaviorally Relevant Neurons Exhibit Plasticity during Adult Motor Learning. Neuron 89, 1173-1179.

Brecht, M., Schneider, M., Sakmann, B., and Margrie, T.W. (2004). Whisker movements evoked by stimulation of single pyramidal cells in rat motor cortex. Nature 427, 704-710.

Brochier, T., Boudreau, M.J., Paré, M., and Smith, A.M. (1999). The effects of muscimol inactivation of small regions of motor and somatosensory cortex on independent finger movements and force control in the precision grip. Exp Brain Res 128, 31-40.

Brown, A.R., and Teskey, G.C. (2014). Motor cortex is functionally organized as a set of spatially distinct representations for complex movements. J Neurosci 34, 13574-13585.

Chen, T.-W., Li, N., Daie, K., and Svoboda, K. (2017). A Map of Anticipatory Activity in Mouse Motor Cortex. Neuron 94, 866-879.e864.

Cheney, P.D., and Fetz, E.E. (1980). Functional classes of primate corticomotoneuronal cells and their relation to active force. J Neurophysiol 44, 773-791.

Cheney, P.D., Fetz, E.E., and Palmer, S.S. (1985). Patterns of facilitation and suppression of antagonist forelimb muscles from motor cortex sites in the awake monkey. Journal of neurophysiology $53,805-820$.

Churchland, M.M., Cunningham, J.P., Kaufman, M.T., Foster, J.D., Nuyujukian, P., Ryu, S.I., and Shenoy, K.V. (2012). Neural population dynamics during reaching. Nature 487, 51-56. 
Churchland, M.M., Cunningham, J.P., Kaufman, M.T., Ryu, S.I., and Shenoy, K.V. (2010). Cortical preparatory activity: representation of movement or first cog in a dynamical machine? Neuron 68, 387-400.

Cunningham, J.P., and Yu, B.M. (2014). Dimensionality reduction for large-scale neural recordings. Nat Neurosci 17, 1500-1509.

Dacre, J., Colligan, M., Ammer, J., Schiemann, J., Clarke, T., Chamosa-Pino, V., Claudi, F., Alex Harston, J., Eleftheriou, C., Pakan, J.M.P., et al. (2019). Cerebellar-recipient motor thalamus drives behavioral context-specific movement initiation. bioRxiv.

Dombeck, D.A., Graziano, M.S., and Tank, D.W. (2009). Functional clustering of neurons in motor cortex determined by cellular resolution imaging in awake behaving mice. J Neurosci $29,13751-13760$.

Economo, M.N., Viswanathan, S., Tasic, B., Bas, E., Winnubst, J., Menon, V., Graybuck, L.T., Nguyen, T.N., Smith, K.A., Yao, Z., et al. (2018). Distinct descending motor cortex pathways and their roles in movement. Nature 563, 79-84.

Esposito, M.S., Capelli, P., and Arber, S. (2014). Brainstem nucleus MdV mediates skilled forelimb motor tasks. Nature 508, 351-356.

Estebanez, L., Hoffmann, D., Voigt, B.C., and Poulet, J.F.A. (2017). Parvalbumin-Expressing GABAergic Neurons in Primary Motor Cortex Signal Reaching. Cell Rep 20, 308-318.

Ferrier, D. (1873). Experimental Researches in Cerebral Physiology and Pathology. Br Med J $1,457$.

Gaidica, M., Hurst, A., Cyr, C., and Leventhal, D.K. (2018). Distinct Populations of Motor Thalamic Neurons Encode Action Initiation, Action Selection, and Movement Vigor. J Neurosci $38,6563-6573$.

Galiñanes, G.L., Bonardi, C., and Huber, D. (2018). Directional Reaching for Water as a Cortex-Dependent Behavioral Framework for Mice. Cell Rep 22, 2767-2783.

Gao, Z., Davis, C., Thomas, A.M., Economo, M.N., Abrego, A.M., Svoboda, K., De Zeeuw, C.I., and Li, N. (2018). A cortico-cerebellar loop for motor planning. Nature 563, 113-116.

Georgopoulos, A.P., Kalaska, J.F., Caminiti, R., and Massey, J.T. (1982). On the relations between the direction of two-dimensional arm movements and cell discharge in primate motor cortex. Journal of Neuroscience 2, 1527-1537.

Georgopoulos, A.P., Merchant, H., Naselaris, T., and Amirikian, B. (2007). Mapping of the preferred direction in the motor cortex. Proc Natl Acad Sci U S A 104, 11068-11072.

Graziano, M.S.A., Taylor, C.S.R., and Moore, T. (2002). Complex movements evoked by microstimulation of precentral cortex. Neuron 34, 841-851.

Guo, J.-Z., Graves, A.R., Guo, W.W., Zheng, J., Lee, A., Rodríguez-González, J., Li, N., Macklin, J.J., Phillips, J.W., Mensh, B.D., et al. (2015). Cortex commands the performance of skilled movement. Elife 4, e10774.

Harrison, T.C., Ayling, O.G., and Murphy, T.H. (2012). Distinct cortical circuit mechanisms for complex forelimb movement and motor map topography. Neuron 74, 397-409. 
Hatsopoulos, N.G., Xu, Q., and Amit, Y. (2007). Encoding of movement fragments in the motor cortex. J Neurosci 27, 5105-5114.

Hira, R., Ohkubo, F., Ozawa, K., Isomura, Y., Kitamura, K., Kano, M., Kasai, H., and Matsuzaki, M. (2013). Spatiotemporal dynamics of functional clusters of neurons in the mouse motor cortex during a voluntary movement. J Neurosci 33, 1377-1390.

Hira, R., Terada, S.-I., Kondo, M., and Matsuzaki, M. (2015). Distinct Functional Modules for Discrete and Rhythmic Forelimb Movements in the Mouse Motor Cortex. J Neurosci 35, $13311-13322$.

Hooks, B.M., Mao, T., Gutnisky, D.A., Yamawaki, N., Svoboda, K., and Shepherd, G.M.G. (2013). Organization of cortical and thalamic input to pyramidal neurons in mouse motor cortex. J Neurosci 33, 748-760.

Hooks, B.M., Papale, A.E., Paletzki, R.F., Feroze, M.W., Eastwood, B.S., Couey, J.J., Winnubst, J., Chandrashekar, J., and Gerfen, C.R. (2018). Topographic precision in sensory and motor corticostriatal projections varies across cell type and cortical area. Nat Commun 9 , 3549 .

Hwang, E.J., Dahlen, J.E., Hu, Y.Y., Aguilar, K., Yu, B., Mukundan, M., Mitani, A., and Komiyama, T. (2019). Disengagement of motor cortex from movement control during longterm learning. Sci Adv 5, eaay0001.

Isomura, Y., Harukuni, R., Takekawa, T., Aizawa, H., and Fukai, T. (2009). Microcircuitry coordination of cortical motor information in self-initiation of voluntary movements. Nature neuroscience 12, 1586.

Jones, E., and Wise, S. (1977). Size, laminar and columnar distribution of efferent cells in the sensory-motor cortex of monkeys. Journal of Comparative Neurology 175, 391-437.

Kaufman, M.T., Churchland, M.M., Ryu, S.I., and Shenoy, K.V. (2014). Cortical activity in the null space: permitting preparation without movement. Nat Neurosci 17, 440-448.

Kaufman, M.T., Seely, J.S., Sussillo, D., Ryu, S.I., Shenoy, K.V., and Churchland, M.M. (2016). The Largest Response Component in the Motor Cortex Reflects Movement Timing but Not Movement Type. eNeuro 3.

Kiritani, T., Wickersham, I.R., Seung, H.S., and Shepherd, G.M. (2012). Hierarchical connectivity and connection-specific dynamics in the corticospinal-corticostriatal microcircuit in mouse motor cortex. J Neurosci 32, 4992-5001.

Kita, T., and Kita, H. (2012). The subthalamic nucleus is one of multiple innervation sites for long-range corticofugal axons: a single-axon tracing study in the rat. J Neurosci 32, 59905999.

Komiyama, T., Sato, T.R., O'Connor, D.H., Zhang, Y.-X., Huber, D., Hooks, B.M., Gabitto, M., and Svoboda, K. (2010). Learning-related fine-scale specificity imaged in motor cortex circuits of behaving mice. Nature 464, 1182-1186.

Kurtzer, I., Herter, T.M., and Scott, S.H. (2005). Random change in cortical load representation suggests distinct control of posture and movement. Nat Neurosci 8, 498-504.

Laubach, M., Wessberg, J., and Nicolelis, M.A. (2000). Cortical ensemble activity increasingly predicts behaviour outcomes during learning of a motor task. Nature 405, 567-571. 
Lawrence, D.G., and Kuypers, H.G. (1968). The functional organization of the motor system in the monkey. I. The effects of bilateral pyramidal lesions. Brain 91, 1-14.

Lemon, R.N. (2008). Descending pathways in motor control. Annu Rev Neurosci 31, 195-218.

Levy, S., Lavzin, M., Benisty, H., Ghanayim, A., Dubin, U., Achvat, S., Brosh, Z., Aeed, F., Mensh, B.D., Schiller, Y., et al. (2020). Cell-Type-Specific Outcome Representation in the Primary Motor Cortex. Neuron, 954-971.

Li, C.X., and Waters, R.S. (1991). Organization of the mouse motor cortex studied by retrograde tracing and intracortical microstimulation (ICMS) mapping. Can J Neurol Sci 18, 28-38.

Li, N., Chen, T.-W., Guo, Z.V., Gerfen, C.R., and Svoboda, K. (2015a). A motor cortex circuit for motor planning and movement. Nature 519, 51-56.

Li, N., Chen, T.W., Guo, Z.V., Gerfen, C.R., and Svoboda, K. (2015b). A motor cortex circuit for motor planning and movement. Nature 519, 51-56.

Masamizu, Y., Tanaka, Y.R., Tanaka, Y.H., Hira, R., Ohkubo, F., Kitamura, K., Isomura, Y., Okada, T., and Matsuzaki, M. (2014). Two distinct layer-specific dynamics of cortical ensembles during learning of a motor task. Nat Neurosci 17, 987-994.

Miri, A., Warriner, C.L., Seely, J.S., Elsayed, G.F., Cunningham, J.P., Churchland, M.M., and Jessell, T.M. (2017). Behaviorally Selective Engagement of Short-Latency Effector Pathways by Motor Cortex. Neuron 95, 683-696.e611.

Moran, D.W., and Schwartz, A.B. (1999). Motor cortical representation of speed and direction during reaching. J Neurophysiol 82, 2676-2692.

Morandell, K., and Huber, D. (2017). The role of forelimb motor cortex areas in goal directed action in mice. Sci Rep 7, 1-14.

Omrani, M., Kaufman, M.T., Hatsopoulos, N.G., and Cheney, P.D. (2017). Perspectives on classical controversies about the motor cortex. J Neurophysiol 118, 1828-1848.

Oswald, M.J., Tantirigama, M.L.S., Sonntag, I., Hughes, S.M., and Empson, R.M. (2013). Diversity of layer 5 projection neurons in the mouse motor cortex. Front Cell Neurosci 7, 174.

Panigrahi, B., Martin, K.A., Li, Y., Graves, A.R., Vollmer, A., Olson, L., Mensh, B.D., Karpova, A.Y., and Dudman, J.T. (2015). Dopamine is required for the neural representation and control of movement vigor. Cell 162, 1418-1430.

Paninski, L., Fellows, M.R., Hatsopoulos, N.G., and Donoghue, J.P. (2004). Spatiotemporal tuning of motor cortical neurons for hand position and velocity. J Neurophysiol 91, 515-532.

Park, J., Coddington, L.T., and Dudman, J.T. (2020). Basal Ganglia Circuits for Action Specification. Annu Rev Neurosci 43, 485-507.

Park, J., Phillips, J.W., Martin, K.A., Hantman, A.W., and Dudman, J.T. (2019). Flexible routing of motor control signals through neocortical projection neuron classes. bioRxiv, 772517.

Peters, A.J., Chen, S.X., and Komiyama, T. (2014). Emergence of reproducible spatiotemporal activity during motor learning. Nature 510, 263-267. 
Peters, A.J., Lee, J., Hedrick, N.G., O'Neil, K., and Komiyama, T. (2017). Reorganization of corticospinal output during motor learning. Nat Neurosci 20, 1133-1141.

Sauerbrei, B.A., Guo, J.-Z., Cohen, J.D., Mischiati, M., Guo, W., Kabra, M., Verma, N., Mensh, B., Branson, K., and Hantman, A.W. (2019). Cortical pattern generation during dexterous movement is input-driven. Nature, 386-391.

Schiemann, J., Puggioni, P., Dacre, J., Pelko, M., Domanski, A., van Rossum, M.C.W., and Duguid, I. (2015). Cellular mechanisms underlying behavioral state-dependent bidirectional modulation of motor cortex output. Cell Rep 11, 1319-1330.

Shepherd, G.M. (2013). Corticostriatal connectivity and its role in disease. Nat Rev Neurosci 14, 278-291.

Stopfer, M., Jayaraman, V., and Laurent, G. (2003). Intensity versus identity coding in an olfactory system. Neuron 39, 991-1004.

Sussillo, D., Churchland, M.M., Kaufman, M.T., and Shenoy, K.V. (2015). A neural network that finds a naturalistic solution for the production of muscle activity. Nature neuroscience 18, 1025-1033.

Svoboda, K., and Li, N. (2018). Neural mechanisms of movement planning: motor cortex and beyond. Curr Opin Neurobiol 49, 33-41.

Tanaka, Y.H., Tanaka, Y.R., Kondo, M., Terada, S.I., Kawaguchi, Y., and Matsuzaki, M. (2018). Thalamocortical Axonal Activity in Motor Cortex Exhibits Layer-Specific Dynamics during Motor Learning. Neuron 100, 244-258 e212.

Thach, W.T. (1978). Correlation of neural discharge with pattern and force of muscular activity, joint position, and direction of intended next movement in motor cortex and cerebellum. $J$ Neurophysiol 41, 654-676.

Ueno, M., Nakamura, Y., Li, J., Gu, Z., Niehaus, J., Maezawa, M., Crone, S.A., Goulding, M., Baccei, M.L., and Yoshida, Y. (2018). Corticospinal Circuits from the Sensory and Motor Cortices Differentially Regulate Skilled Movements through Distinct Spinal Interneurons. Cell Rep 23, 1286-1300.e1287.

Wang, L., Conner, J.M., Rickert, J., and Tuszynski, M.H. (2011). Structural plasticity within highly specific neuronal populations identifies a unique parcellation of motor learning in the adult brain. Proc Natl Acad Sci U S A 108, 2545-2550.

Wang, X., Liu, Y., Li, X., Zhang, Z., Yang, H., Zhang, Y., Williams, P.R., Alwahab, N.S.A., Kapur, K., Yu, B., et al. (2017). Deconstruction of Corticospinal Circuits for Goal-Directed Motor Skills. Cell 171, 440-455.e414.

Wei, Z., Inagaki, H., Li, N., Svoboda, K., and Druckmann, S. (2019). An orderly single-trial organization of population dynamics in premotor cortex predicts behavioral variability. Nat Commun 10, 1-14.

Weiler, N., Wood, L., Yu, J., Solla, S.A., and Shepherd, G.M.G. (2008). Top-down laminar organization of the excitatory network in motor cortex. Nat Neurosci 11, 360-366.

Yakovenko, S., and Drew, T. (2015). Similar Motor Cortical Control Mechanisms for Precise Limb Control during Reaching and Locomotion. J Neurosci 35, 14476-14490. 
Yttri, E.A., and Dudman, J.T. (2016). Opponent and bidirectional control of movement velocity in the basal ganglia. Nature 533, 402-406.

\section{Acknowledgments}

We are grateful to Gülsen Sürmeli, Matt Nolan and members of the Nolan, Duguid and Sürmeli labs for experimental discussions and for comments on the manuscript. Nick Steinmetz for the suggested design of the author contribution matrix. AAV-GCaMP6s was a gift from Douglas Kim \& GENIE Project (Addgene 100844-AAV1). Confocal microscopy was performed in the IMPACT Imaging Facility at the University of Edinburgh. Research was supported by grants from the Biotechnology and Biological Sciences Research Council (BB/R018537/1 to I.D.), DFG fellowship program (AM 443/1-1 to J.A.), the Shirley Foundation, Simons Initiative for the Developing Brain (SIDB) PhD studentship (C.E.), A*STAR PhD studentship (B.P.) and a Wellcome Senior Research Fellowship (110131/Z/15/Z to I.D.).

\section{Author contributions}

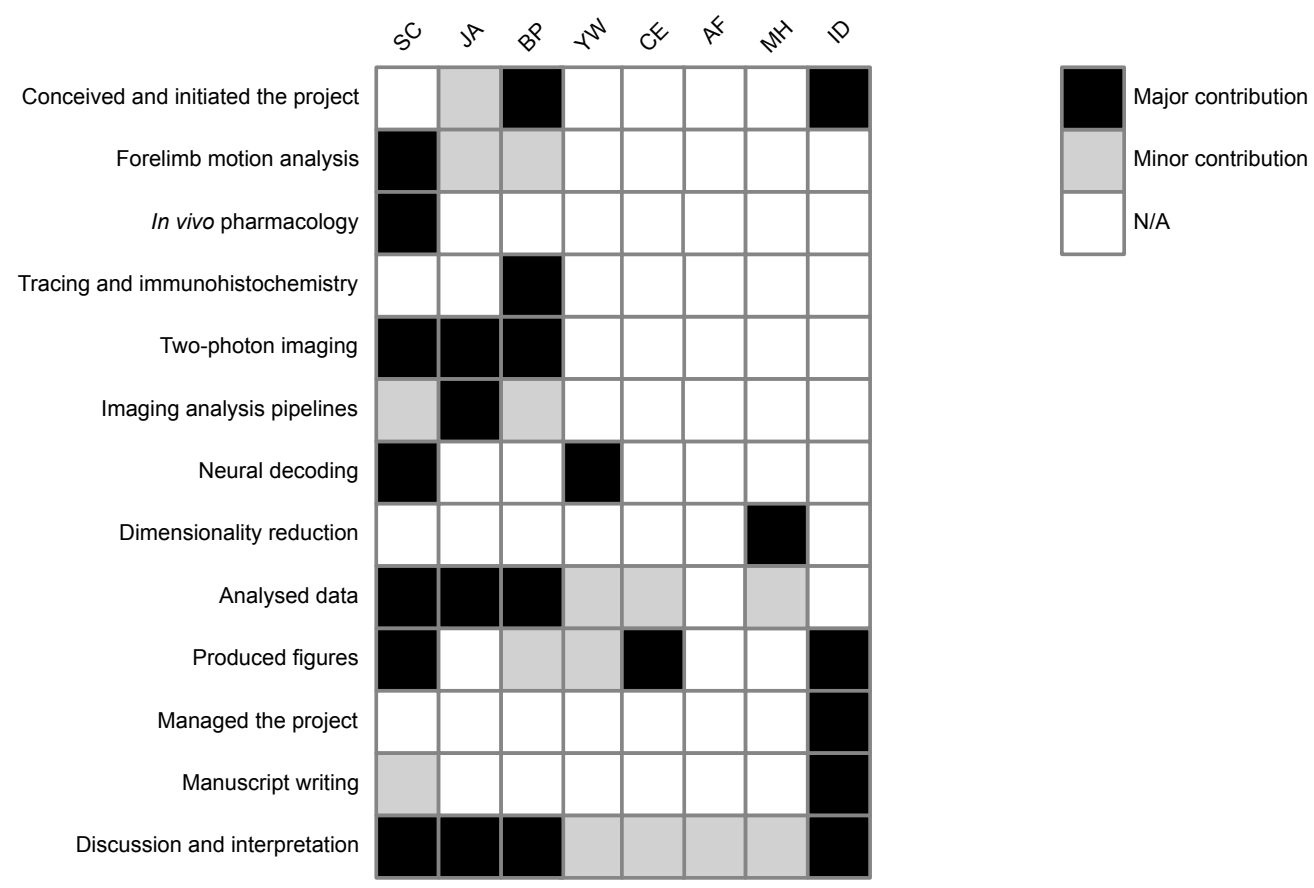

\section{Methods}

\section{Animal husbandry and general surgery}

Male adult C57BL/6J wild-type mice (5-12 weeks old, 20-30g, 1-4 animals per cage) were maintained on a reversed 12:12 hour light:dark cycle and provided ad libitum access to food and water as well as environmental enrichment. All experiments and procedures were 
approved by the University of Edinburgh local ethical review committee and performed under license from the UK Home Office in accordance with the Animal (Scientific Procedures) Act 1986. Surgical procedures were performed under $\sim 1.5 \%$ isoflurane anaesthesia and each animal received fluid replacement therapy $(0.5 \mathrm{ml}$ sterile Ringer's solution), buprenorphine $(0.05 \mathrm{mg} / \mathrm{kg})$ and either carprofen $(4 \mathrm{mg} / \mathrm{kg})$ or dexamethasone $(2 \mathrm{mg} / \mathrm{kg})$ for pain relief and to reduce inflammation. At 24 and 48 hours Carprofen $(4 \mathrm{mg} / \mathrm{kg})$ was administered for postoperative pain relief. Craniotomies, centred on $1.6 \mathrm{~mm}$ lateral, $0.6 \mathrm{~mm}$ rostral relative to bregma, were performed in a stereotactic frame (David Kopf Instruments, CA, USA) using a hand-held dentist drill with $0.5 \mathrm{~mm}$ burr. A small lightweight headplate $(0.5 \mathrm{~g})$ was implanted on the surface of the skull using cyanoacrylate glue and dental cement (Lang Dental, IL, USA) and mice were left for at least 48 hours to recover.

\section{Behavioural training}

After recovery from head plate surgery, mice were handled extensively before being head restrained and habituated to a custom forelimb lever abduction-adduction behavioural setup. Mice were trained to perform two diametrically opposing movements - a $4 \mathrm{~mm}$ abduction (extension of the forelimb away from the body) or adduction (retraction of the forelimb towards the body) - in response to a $6 \mathrm{kHz}$ auditory cue to obtain a water reward ( $\sim \mu \mathrm{l})$. To increase task engagement, mice were placed on a water control paradigm $(1 \mathrm{ml} /$ day) and weighed daily to ensure body weight remained above $85 \%$ of baseline. Mice were trained once per day for 30 mins and advanced through different phases of the task once they achieved at least 50 rewards in each of two consecutive sessions. Initially, mice were required to perform uncued abduction and adduction movements to obtain rewards, prior to the introduction of an auditory cue with pseudo-random inter-trial-interval (ITI) of 6-8s and a response window of $10 \mathrm{~s}$ window. The response window was gradually reduced to $2 \mathrm{~s}$ across training sessions.

\section{Forelimb kinematic tracking}

A motion index was calculated from high speed videos (60fps, Prosilica GC780C, Allied Vision, Germany or $300 \mathrm{fps}$ for in vivo pharmacology, Mako U U-029, Allied Vision) of mouse behaviour acquired using Streampix 7 (Norpix, Canada). A rectangular region of interest (ROI) was drawn around the left forelimb and the frame-to-frame difference in pixel intensity was calculated using the formula: $M I_{f}=\sum_{i=1}^{N}\left(c_{f+1, i}-c_{f, i}\right)^{2}$, where $c f, i$ is the grayscale level of pixel $i$ in the frame $f$. Motion index was aligned to behaviourally-relevant time points (lever displacement, cue presentation etc), with videos and behaviour resampled to a common sampling rate. Motion index onsets were calculated by aligning the smoothed traces (40-point 
loess filter) to the lever movement and identifying the last point prior to movement where mean motion index was $>$ threshold (mean upper bound of 95\% confidence interval during baseline).

\section{In vivo pharmacology}

Mice trained to expert level had a small burr hole opened directly above caudal forelimb area (CFA; $1.6 \mathrm{~mm}$ lateral, $0.6 \mathrm{~mm}$ rostral to bregma) before recovering for $>90$ mins. After $10 \mathrm{~min}$ of behaviour, the lever was locked and a small volume of the $\mathrm{GABA}_{\mathrm{A}}$ receptor agonist muscimol (200nl of $2 \mathrm{mM}$ stock dissolved in external saline solution containing $150 \mathrm{mM} \mathrm{NaCl}, 2.5 \mathrm{mM}$ $\mathrm{KCl}, 10 \mathrm{mM}$ HEPES, $1.5 \mathrm{mM} \mathrm{CaCl}_{2}$ and $1 \mathrm{mM} \mathrm{MgCl}_{2}$, adjusted to $\mathrm{pH}$ 7.3) or saline (vehicle only) was injected into the target area (AP: 0.6, ML: 1.6, DV: $-0.7 \mathrm{~mm}$ ). Behavioural metrics were analysed from 10 mins post injection and the experimenter was blinded to drug versus control groups.

\section{Retrograde tracing}

To selectively label pyramidal tract (PT-type) neurons in layer 5B of CFA, red RetroBeads (Lumafluor, USA) were injected into the pons ( $4.0 \mathrm{~mm}$ caudal and $0.4 \mathrm{~mm}$ lateral of bregma), delivered via pulled glass pipettes ( $5 \mu \mathrm{l}$, Drummond Scientific, PA, USA; $10-20 \mathrm{nl} / \mathrm{min}$ ) using an automated injection system (Model Picospritzer iii, Parker, NH, USA). Injections were made at 4 sites (100 nl / site) located 200,400, 600 and $800 \mu \mathrm{m}$ dorsal from the cranial floor. After $>14$ days post-injection, mice were terminally anaesthetised using an intraperitoneal injection of a ketamine/domitor mixture $(75 \mathrm{mg} / \mathrm{kg}$ ketamine, $1 \mathrm{mg} / \mathrm{kg}$ domitor) and transcardially perfused with $30 \mathrm{ml}$ of phosphate-buffered saline (PBS) followed by $30 \mathrm{ml}$ of $4 \%$ paraformaldehyde (PFA, Sigma-Aldrich, MO, USA), dissolved in PBS and adjusted to $\mathrm{pH} 7.4$. Brains were post-fixed at $4{ }^{\circ} \mathrm{C}$ for $1-3$ days in $4 \%$ PFA solution, then transferred to PBS solution. Individual brains were cut into coronal sections $(60 \mu \mathrm{m})$ using a vibrating microtome (Leica VT1200 S, Leica Microsystems (UK) Ltd.), mounted with Vectashield Antifade Mounting Medium (Vector Laboratories, CA, USA) and sealed with a glass coverslip. Images were acquired with a Leica DM $R$ epifluorescence microscope and image analysis was performed using ImageJ (Rueden et al., 2017) and MATLAB (MathWorks, MA, USA). To obtain estimates of the depth of layer 5B in CFA, 3 coronal sections from each brain were imaged $(0.54 \mathrm{~mm}$, $0.6 \mathrm{~mm}$ and $0.66 \mathrm{~mm}$ rostral to bregma). Brightness/contrast adjustments and background subtraction (rolling ball, 30 pixels wide at $1.28 \mu \mathrm{m} /$ pixel; Fiji (Schindelin et al., 2012) functions were performed to reduce the contribution of background autofluorescence. Each ROI was then divided into $25-\mu \mathrm{m}$-deep bins that were normalised to a value between 0 and 1 , with 0 being the darkest bin and 1 being the brightest bin and all bins were compared to baseline. In order to obtain a depth profile of layer 5B within CFA, the depth of the dorsal-most retrogradely 
labelled neuron was recorded at $100 \mu \mathrm{m}$ intervals from $1.3-1.9 \mathrm{~mm}$ lateral of bregma and repeated in 5 sequential coronal sections from $0.36-0.84 \mathrm{~mm}$ rostral of bregma. For each mouse, the depth of layer 5B at the centre of CFA ( $1.6 \mathrm{~mm}$ lateral, $0.6 \mathrm{~mm}$ rostral to bregma) was taken as the reference depth and the depths of other locations reported relative to this value.

\section{Immunohistochemistry}

Mice expressing GCaMP6s were transcardially perfused and horizontal sections $(30 \mu \mathrm{m})$ were cut parallel to the surface of CFA. Sections were rinsed in PBS overnight, incubated with a blocking solution (PBS, with 0.5\% Triton X-100 (Sigma-Aldrich) and 10\% goat serum (SigmaAldrich)) for $2 \mathrm{hrs}$ and rinsed with PBS. Sections were incubated overnight with mouse antiNeuN (MAB377 Anti-NeuN Antibody, clone A60, Sigma-Aldrich) diluted 1:1500 in carrier solution (PBS, with $0.5 \%$ Triton $\mathrm{X}-100$ and $1 \%$ goat serum), then rinsed with PBS. For secondary antibody binding, sections were incubated overnight with goat anti-mouse Alexa Fluor 568 (Invitrogen, MA, USA) diluted 1:750 in carrier solution then rinsed with PBS. Sections were mounted onto glass slides, briefly air-dried, covered with Vectashield Antifade Mounting Medium (Vector Laboratories), and sealed with a glass coverslip. Images of CFA were acquired using a Nikon A1R FLIM confocal microscope (20X objective lens, 0.8 NA, Plan Apo VC, Nikon, Europe). Three images were taken at imaging planes corresponding to layer 5B (550 $\mu \mathrm{m}$ from the cortical surface). The number of cells in each image was manually counted and divided by the area to obtain a measure of neuron density. For most fields-ofview (FOVs) recorded during calcium imaging, neurons were not visible in all portions of the frame due to occlusion by blood vessels. Polygons were drawn around visible neurons in each field-of-view to provide a realistic estimate of the imaging area.

\section{2-photon imaging}

To perform population calcium imaging in layer 5B of CFA, $200 \mathrm{nl}$ of AAV1-SynGCaMP6s (2.9x10 ${ }^{13} \mathrm{GC} / \mathrm{ml}$, Addgene 100844-AAV1) was injected into contralateral motor cortex (AP: 0.6, ML: 1.6, DV: $0.6 \mathrm{~mm}$ ) via pulled glass pipettes ( $5 \mu \mathrm{l}$, Drummond Scientific; $10-20 \mathrm{nl} / \mathrm{min}$ ) using an automated injection system (Model Picospritzer iii, Parker), before sealing the craniotomy with silicone (Body Double; Smooth-On, PA, USA) and implanting a lightweight headplate. For imaging a cranial window, a glass coverslip (\#0; Menzel-Gläser, Germany; 2photon imaging)was fixed in place with cyanoacrylate glue was implanted above the virus injection site. 2-photon calcium imaging was performed using a custom-built resonant scanning 2-photon microscope (320 × $320 \mu \mathrm{m}$ field-of-view; $600 \times 600$ pixels) with a Ti:Sapphire pulsed laser (Chameleon Vision-S, Coherent, CA, USA; $<70$ fs pulse width, 80 $\mathrm{MHz}$ repetition rate) tuned to $920 \mathrm{~nm}$ wavelength. Images were acquired at $40 \mathrm{~Hz}$ with a $40 \mathrm{x}$ 
objective lens (0.8 NA; Nikon) with custom-programmed LabVIEW-based software (LotoScan). Motion artefacts in the raw fluorescence videos were corrected using discrete Fourier 2-dimensional-based image alignment (SIMA 1.3.2; (Kaifosh et al., 2014)). ROls were drawn manually in Fiji and pixel intensity within each ROI averaged to produce a raw fluorescence time series $(F)$. To remove fluorescence originating from neuropil and / or neighbouring neurons, fluorescence signals were decontaminated and extracted using nonnegative matrix factorisation, as implemented in FISSA (Keemink et al., 2018). Normalized fluorescence was calculated as $\Delta F / F_{0}$, where $F_{0}$ was calculated as the 5 th percentile of the $1 \mathrm{~Hz}$ low-pass filtered raw fluorescence signal and $\Delta F=F-F_{0}$. All further analyses were performed in custom written scripts in MATLAB or Python v 3.7, freely available via the Duguid Lab GitHub repository (https://github.com/DuguidLab). In order to define movement-related neurons, we first defined a baseline ( -1.5 to $-0.5 \mathrm{~s}$ relative to motion index onset) and perimovement (-0.15 s from motion index onset to $+1.5 \mathrm{~s}$ after lever movement) epochs. Movement-related neurons were identified by two independent methods: 1) bootstrapped distribution (10,000 samples) of baseline-to-peak values (mean of the $100 \mathrm{~ms}$ centred on the largest deviation from baseline within the peri-movement epoch - mean of baseline epoch) were compared with the baseline - traces were smoothed with a 40 frame loess filter; 2) bootstrapped distributions of $\Delta \mathrm{F} / \mathrm{F}_{0}$ in $250 \mathrm{~ms}$ bins within the peri-movement epoch were compared with baseline. If either method identified significant differences the neuron was classified as movement-related. $\Delta F / F_{0}$ onsets were calculated using a previously published onset detection algorithm using a slope sum function (SSF; (Zong et al., 2003)) with the decision rule and window of the SSF adapted to calcium imaging data (threshold $10 \%$ of peak, SSF window $375 \mathrm{~ms}$, smoothed with a Savitzky Golay filter across 27 frames with order 2) and reported as the median of 10,000 bootstrapped samples to reduce the influence of noisy individual trials. Neurons with onsets beyond the peri-movement window were defined as 'reward phase' neurons. Neurons with action bias were detected using the same classification criteria described above but across actions (i.e. significant differences in bootstrapped $\Delta \mathrm{F} / \mathrm{F}_{0}$ baseline-to-peak or $250 \mathrm{~ms}$ peri-movement bins).

\section{Neural decoding}

To decode action-type in single neurons we employed a Naïve Bayes classifier, where distributions of features are assumed to be Gaussian. Motion index-aligned $\Delta F / F_{0}$ data were assessed within a $10 \mathrm{~s}$ peri-movement window to produce a time series for the decoding accuracy. At each time point, leaving one trial out (test trial), the likelihood of determining abduction or adduction was based on the remaining trials (training set). For cross-validation, the leave-one-out procedure was then repeated by looping over trials. The resulting decoding accuracy time series were analysed within a peri-movement epoch - the peri-movement epoch 
began at $-0.15 \mathrm{~s}$ relative to motion index onset and ended based on the peak $\Delta F / F_{0}$ response of each neuron; the position of the median peak was calculated for each action type and the later of these time points used as the cut off. To identify neurons with decoding performance above chance, the bootstrapped distributions of decoding accuracy scores were compared against a threshold value for each session. Only neurons with at least 1 bin significantly higher than threshold were defined as high decoding accuracy. The threshold for each session was calculated based on modelled data composed of random samples from a Gaussian distribution with the same number of trials as the experimental data. For each session, modelled data accuracy was calculated 1000 times, assuming a prior probability of 50:50, and the mean $\pm 2 \mathrm{SD}$ was used as the threshold for significance. For population level classification of action type, we employed logistic regression. As above, the decoding accuracy of time series for each population was generated via leave-one-out design looped over all the trials in a given session. Population decoding accuracy was defined as the maximum decoding accuracy in any $250 \mathrm{~ms}$ bin within the peri-movement epoch. Population decoding was also performed on subsets of the entire population. Neurons were removed from the population one at a time, either in order from highest to lowest decoding accuracy score or randomly. The process was repeated 25 times in the random condition and the median of all responses used as the representative example for comparison with the ordered removal condition. Subpopulations of neurons decoding significantly above chance were determined by comparing decoding scores with a shuffled dataset (sampled randomly from 1000 time points with the trial labels (abduction or adduction) randomised for each sample). If confidence intervals from the population data did not overlap with those of the shuffled data, population scores were deemed to be above chance. In 3/12 FOVs with low proportions of high decoding neurons and trial numbers, the population decoding accuracy was never significantly above chance. These FOVs were excluded from the comparison between ordered and random removal of neurons.

\section{Dimensionality reduction}

Raw fluorescence traces for all trials with successful movements in a $7.5 \mathrm{~s}$ peri-movement window were concatenated, filtered with a three frame $(120 \mathrm{~ms})$ wide boxcar kernel, whitened and transformed with principal component analysis. The principal components (PCs) corresponding to the 16 highest eigenvalues, which corresponded to an average $83 \%$ (range $77 \%, 94 \%$ ) cumulative explained variance, were analysed. To compute trajectories in PC space, PC projections for all trials were averaged (separately for abduction or adduction) and the variance and $95 \%$ confidence intervals for each time point estimated via 100-fold bootstrapping. The separability of the trajectories for abduction or adduction was computed in each PC separately as $d^{\prime}(t)=\left|m_{a b d}(t)-m_{a d d}(t)\right| / \sqrt{ } 0.5\left(v_{a b d}(t)+v_{\text {add }}(t)\right)$, where $m_{a b d}(t)$ and $m_{\text {add }}(t)$ 
are the mean trajectories for abduction and adduction, and $v_{a b d}(t)$ and $v_{\text {add }}(t)$ the corresponding variances, estimated from trials. The separability $d^{\prime}(t)$ was bootstrapped from 200 samples, and variance and $95 \%$ confidence intervals estimated from this sample. $d^{\prime}(t)$ was computed for all frames from movement onset to termination, where the latter was the longest time of movement execution recorded in each session. PCs were considered separable if the difference between $d^{\prime}(t)$ and $d_{\text {shuffle }}(t)$ (obtained in the same way from trial-shuffled data) was within the $95 \%$ confidence interval, which was estimated from the sum of the relevant bootstrapped variances. For each FOV, the largest significant $d^{\prime}(t)$ was used; in 2/13 FOVs no PCs showed significant separability (these two FOVs also had a chance level population decoding score), and were excluded in the summary data.

\section{Spatiotemporal organisation}

To assess the functional (temporal) organisation of simultaneously recorded populations of neurons, pairwise correlation coefficients (Pearson's $r$ ) from the motion index-aligned $\Delta F / F_{0}$ within the peri-movement epoch were compared - traces were smoothed with a 40 point loess filter. Data were split based on their decoding accuracy scores and the bootstrapped median difference between high decoding accuracy neurons and those of the population were subtracted and a median difference calculated per sample. This process was repeated 10,000 times to generate a distribution for high decoding neurons versus the entire population and the same sampling procedure was used to investigate the correlations within low decoding accuracy neurons. To investigate spatial clustering, bootstrapped median differences between high decoding accuracy neurons and the population using pairwise distances (defined as the Euclidean distance between the centroids of manually drawn ROls from 2-photon imaging processing) were compared. A Generalised Linear Mixed-Effects Model:

$$
r \sim \text { distance }_{\text {pairwise }} \times \text { accuracy }_{\text {decoder }}+\text { action }_{\text {type }}+\text { animal }
$$

was used to model the pairwise correlation coefficient as a function of pairwise distance (continuous), decoding accuracy and action type. Pairwise distance and decoding accuracy were modelled as interacting fixed terms, while action type and animal were modelled as random intercepts to account for the dependency of the measurements on observations from the same animal and across the different action types. The model was estimated using the restricted maximum likelihood, or REML, method (Bartlett and Fowler, 1937). Model assumptions were verified by comparing residual versus fitted values for each covariate in the model against each covariate removed from the model.

\section{Statistics}


Data analysis was performed using custom-written scripts in MATLAB 2019a or Python v3.7. Data are reported as mean $\pm 95 \%$ bootstrapped confidence interval (10,000 bootstrap samples) unless otherwise indicated. Where multiple measurements were made from a single animal, suitable weights were used to evaluate summary population statistics. Statistical significance was considered when $\mathrm{P}<0.05$ unless otherwise stated. Data were tested for normality and parametric/non-parametric tests were used as appropriate and as detailed in the text. The GLMM was designed in Python using the statsmodels library (Seabold and Perktold, 2010).

\section{References (for methods)}

Bartlett, M.S., and Fowler, R.H. (1937). Properties of sufficiency and statistical tests. Proceedings of the Royal Society of London Series A - Mathematical and Physical Sciences $160,268-282$.

Kaifosh, P., Zaremba, J.D., Danielson, N.B., and Losonczy, A. (2014). SIMA: Python software for analysis of dynamic fluorescence imaging data. Front Neuroinform 8, 80.

Keemink, S.W., Lowe, S.C., Pakan, J.M.P., Dylda, E., van Rossum, M.C.W., and Rochefort, N.L. (2018). FISSA: A neuropil decontamination toolbox for calcium imaging signals. Sci Rep $8,3493$.

Rueden, C.T., Schindelin, J., Hiner, M.C., DeZonia, B.E., Walter, A.E., Arena, E.T., and Eliceiri, K.W. (2017). ImageJ2: ImageJ for the next generation of scientific image data. BMC Bioinformatics 18, 529.

Schindelin, J., Arganda-Carreras, I., Frise, E., Kaynig, V., Longair, M., Pietzsch, T., Preibisch, S., Rueden, C., Saalfeld, S., Schmid, B., et al. (2012). Fiji: an open-source platform for biological-image analysis. Nat Methods 9, 676-682.

Seabold, S., and Perktold, J. (2010). Statsmodels: Econometric and statistical modeling with python. Paper presented at: Proceedings of the 9th Python in Science Conference (Austin, TX).

Zong, W., Heldt, T., Moody, G.B., and Mark, R.G. (2003). An open-source algorithm to detect onset of arterial blood pressure pulses. In Computers in Cardiology, 2003 (ieeexplore.ieee.org), pp. 259-262. 


\section{Table of results}

$\begin{array}{clll}\bar{X}=\text { mean } & \tilde{X}=\text { median } & \text { SD }=\text { standard deviation } & \text { IQR }=\text { interquartile range } \\ \text { abd. = abduction } & \text { add. = adduction } & \text { fov = fields-of-view } & \mathrm{H} / \mathrm{LDA}=\text { high } / \text { low decodi }\end{array}$

$\mathrm{H} / \mathrm{LDA}=$ high / low decoding accuracy

$A B=$ action bias GLMM = generalised linear mixed-effects model

\begin{tabular}{|c|c|c|c|c|c|c|}
\hline Figure & Description & Sample size & Result & Variance & $\begin{array}{l}\text { Confidence } \\
\text { intervals }(95 \%)\end{array}$ & $\begin{array}{l}\text { Statistical test } \\
\text { result }\end{array}$ \\
\hline $1 \mathrm{D}-\mathrm{F}$ & Training time (days) & $N=12$ & $\bar{X}=12.8$ & $\mathrm{SD}=2.6$ & {$\left[\begin{array}{lll}11.3 & 14.2\end{array}\right]$} & \\
\hline $1 \mathrm{E}$ & Successful trials / session (abd. / add.) & $N=12$ & $\bar{X}=41.3 / 42.3$ & $\mathrm{SD}=7.2 / 7.2$ & $\begin{array}{l}{[37.545 .2] /[38.4} \\
45.9]\end{array}$ & \\
\hline $1 \mathrm{~F}$ & Vigour (ms; abd. / add.) & $N=12$ & $\tilde{X}=713.5 / 566$ & $\begin{array}{l}\text { IQR }=[711722.5] / \\
{[552567]}\end{array}$ & $\begin{array}{l}{[706.5733 .5] /} \\
{[537.25573]}\end{array}$ & \\
\hline \multirow[t]{4}{*}{$1 \mathrm{H}$} & Norm. task success (\%; abd. saline) & $N=6$ & $\begin{array}{l}\bar{X}=0.99 / 1.19 \\
/ 1.47\end{array}$ & $\begin{array}{l}S D=0.49 / 0.79 / \\
0.65\end{array}$ & $\begin{array}{l}{[0.661 .31] /[0.67} \\
1.74] /[1.041 .93]\end{array}$ & \multirow{2}{*}{$\begin{array}{l}\mathrm{F}(1,2)=2.25, P= \\
1.4 \times 10^{-2} / 2.8 \times 10^{-2} / \\
0.3\end{array}$} \\
\hline & Norm. task success (\%; abd. muscimol) & $N=6$ & $\begin{array}{l}\bar{X}=0.34 / 0.25 / \\
1.52\end{array}$ & $\begin{array}{l}S D=0.19 / 0.14 / \\
0.60\end{array}$ & $\begin{array}{l}{[0.220 .47] /[0.15} \\
0.34] /[1.111 .96]\end{array}$ & \\
\hline & Norm. task success (\%; add. saline) & $N=6$ & $\begin{array}{l}\bar{X}=0.81 / 0.88 \\
/ 0.99\end{array}$ & $\begin{array}{l}S D=0.09 / 0.26 / \\
0.40\end{array}$ & $\begin{array}{l}{[0.76-0.88] /[0.68} \\
1.03] /[0.761 .28]\end{array}$ & \multirow{2}{*}{$\begin{array}{l}\mathrm{F}(1,2)=1.62, P= \\
3.2 \times 10^{-3} / 2.7 \times 10^{-2} / \\
0.9\end{array}$} \\
\hline & Norm. task success (\%; add. muscimol) & $N=6$ & $\begin{array}{l}\bar{X}=0.35 / 0.48 \\
/ 0.98\end{array}$ & $\begin{array}{l}S D=0.24 / 0.31 / \\
0.41\end{array}$ & $\begin{array}{l}{[0.200 .53] /\left[\begin{array}{ll}0.28 \\
0.69] /[0.74 & 1.28\end{array}\right]}\end{array}$ & \\
\hline $\begin{array}{l}\text { Supp. } \\
1 C\end{array}$ & Neurons / $100 \mu m^{2}$ (NeuN / GCaMP6s) & $\begin{array}{l}N=1 / 7 \\
\text { fov }=3 / 15\end{array}$ & $\bar{X}=15.6 / 13.3$ & $S D=0.9 / 2.7$ & & $\mathrm{t}(16)=1.75, P=0.2$ \\
\hline $2 \mathrm{D}$ & $\begin{array}{l}\text { Prop. of responsive neurons (non / } \\
\text { movement / reward) }\end{array}$ & $\begin{array}{l}N=6 \\
\text { fov }=12 \\
\text { cell }=653\end{array}$ & $\begin{array}{l}\bar{X}=20.9 / 73.5 \\
/ 5.7\end{array}$ & $\begin{array}{l}\mathrm{SD}=15.1 / 16.0 / \\
3.7\end{array}$ & $\begin{array}{l}{[12.829 .1] /[64.7} \\
81.8] /[3.77 .7]\end{array}$ & \\
\hline
\end{tabular}




\begin{tabular}{|c|c|c|c|c|c|}
\hline $2 \mathrm{~F}$ & $\begin{array}{l}\text { Prop. of movement-responsive neurons } \\
\text { (non / abd. / add.) }\end{array}$ & $\begin{array}{l}N=6 \\
\text { fov }=12 \\
\text { cell }=468\end{array}$ & $\begin{array}{l}\tilde{X}=59.8 / 14.3 / \\
11.8\end{array}$ & $\begin{array}{l}\text { IQR }=[42.974 .3] / \\
{[12.728 .6] /[8.2} \\
27.7]\end{array}$ & \\
\hline $\begin{array}{l}\text { Supp. } \\
2 \mathrm{~A}\end{array}$ & Action bias cell types $(\% ; \mathrm{I}-\mathrm{VI})$ & $\begin{array}{l}N=6 \\
\text { fov }=12 \\
\text { cell }=181\end{array}$ & $\begin{array}{l}75(136) / 10(19) \\
/ 7(12) / 4(7) / \\
3(5) / 1(2)\end{array}$ & & \\
\hline $\begin{array}{l}\text { Supp. } \\
2 \text { C }\end{array}$ & $\begin{array}{l}\text { Prop. of biased neurons (equal / unequal } \\
\text { baseline) }\end{array}$ & $\begin{array}{l}N=6 \\
\text { fov }=12 \\
\text { cell }=181\end{array}$ & $\tilde{X}=69.5 / 30.5$ & $\begin{array}{l}\text { IQR = [63.2 71.4] / } \\
{[28.636 .8]}\end{array}$ & \\
\hline $2 \mathrm{~J}$ & $\begin{array}{l}\text { Prop. of biased neurons (highDA / } \\
\text { lowDA) }\end{array}$ & $\begin{array}{l}N=6 \\
\text { fov }=12 \\
\text { cell }=181\end{array}$ & $\tilde{X}=67.3 / 32.7$ & $\begin{array}{l}\text { IQR }=[42.679 .3] / \\
{[20.757 .4]}\end{array}$ & \\
\hline $2 \mathrm{~K}$ & $\begin{array}{l}\text { Prop. of movement-responsive neurons } \\
\text { (LDA / HDA+AB / HDA-AB) }\end{array}$ & $\begin{array}{l}N=6 \\
\text { fov }=12 \\
\text { cell }=468\end{array}$ & $\begin{array}{l}\tilde{X}=60.5 / 27.1 / \\
11.1\end{array}$ & $\begin{array}{l}\mathrm{IQR}=[34.778 .1] / \\
{[11.851] /[5.714 .3]}\end{array}$ & \\
\hline 3B & $\begin{array}{l}\text { Decoding accuracy (single cell / } \\
\text { population) }\end{array}$ & $\begin{array}{l}N=6 \\
\text { fov }=12\end{array}$ & $\tilde{X}=0.61 / 0.75$ & $\begin{array}{l}\text { IQR }=\left[\begin{array}{ll}0.58 & 0.65\end{array}\right] / \\
{[0.630 .79]}\end{array}$ & $\begin{array}{l}W=1, Z=-2.20, P \\
=2.8 \times 10^{-2}\end{array}$ \\
\hline $3 F$ & $\begin{array}{l}\text { Prop. neurons removed (high-low / } \\
\text { random) }\end{array}$ & $\begin{array}{l}N=6 \\
\text { fov }=9\end{array}$ & $\tilde{X}=0.21 / 0.64$ & $\begin{array}{l}\text { IQR }=\left[\begin{array}{ll}0.11 & 0.61\end{array}\right] / \\
{[0.410 .98]}\end{array}$ & $\begin{array}{l}W=1, Z=-2.20, P \\
=2.8 \times 10^{-2}\end{array}$ \\
\hline $\begin{array}{l}\text { Supp. } \\
3 A\end{array}$ & Population decoding vs max d' & $\begin{array}{l}N=6 \\
\text { fov }=10\end{array}$ & & & $\begin{array}{l}\mathrm{r} 2=0.89, \mathrm{~F}(1,5)= \\
33.6, P=4.3 \times 10^{-3}\end{array}$ \\
\hline $3 \mathrm{~J}$ & $\begin{array}{l}\text { Prop. neurons removed (high-low / } \\
\text { random) }\end{array}$ & $\begin{array}{l}N=6 \\
\text { fov }=10\end{array}$ & $\tilde{X}=0.15 / 0.35$ & $\begin{array}{l}\text { IQR }=\left[\begin{array}{ll}0.05 & 0.47]\end{array}\right] \\
{[0.110 .85]}\end{array}$ & $\begin{array}{l}W=1, Z=-2.20, P \\
=3.1 \times 10^{-2}\end{array}$ \\
\hline 4B & $\begin{array}{l}\text { Norm. prop. } \triangle F / F_{0} \text { onsets abduction (ms; } \\
\text { HDA / LDA). ANOVA [animal:cell type: } \\
\text { onset time] }\end{array}$ & $\begin{array}{l}N=6 \\
\text { fov }=12 \\
\text { cell }=468\end{array}$ & $\tilde{X}=119 / 85$ & $\begin{array}{l}\text { IQR }=\left[\begin{array}{ll}83.3 & 142.9\end{array}\right] / \\
{[76.9101 .9]}\end{array}$ & $\begin{array}{l}\mathrm{F}(5)=0.43, P= \\
0.83 / \mathrm{F}(1)=0.19, P \\
=0.66 / \mathrm{F}(12)= \\
5.83, P=7.4 \times 10^{-7}\end{array}$ \\
\hline
\end{tabular}




\begin{tabular}{|c|c|c|c|c|c|c|}
\hline & $\begin{array}{l}\text { Norm. prop. } \Delta F / F_{0} \text { onsets adduction (ms; } \\
\text { HDA / LDA). ANOVA [animal:cell type: } \\
\text { onset time] }\end{array}$ & $\begin{array}{l}N=6 \\
\text { fov }=12 \\
\text { cell }=468\end{array}$ & $\tilde{X}=167 / 78$ & $\begin{array}{l}\text { IQR }=[95.2177 .4] / / \\
{[67.889 .8]}\end{array}$ & & $\begin{array}{l}\mathrm{F}(5)=0.43, P= \\
0.81 / \mathrm{F}(1)=0.19, P \\
=0.12 / \mathrm{F}(12)= \\
5.83, P=3.3 \times 10^{-14}\end{array}$ \\
\hline $4 \mathrm{C}$ & $\begin{array}{l}\text { Pairwise correlation coefficient ( } r \text {; } \\
\text { abduction; HDA vs ALL / LDA vs ALL) }\end{array}$ & $\begin{array}{l}N=6 \\
\text { fov }=12 \\
\text { cell }=468\end{array}$ & $\tilde{X}=-0.02 / 0.02$ & & $\begin{array}{l}{[-0.220 .14] /[-0.12} \\
0.17]\end{array}$ & $P=0.85 / 1.0$ \\
\hline \multirow[t]{2}{*}{$4 \mathrm{D}$} & $\begin{array}{l}\text { Pairwise corr. Vs distance (HDA / LDA / } \\
\text { ALL) }\end{array}$ & $\begin{array}{l}N=6 \\
\text { fov }=12 \\
\text { cell }=468 \\
n=33 \text { DA } \\
\text { bins }\end{array}$ & $\begin{array}{l}\text { Spearman } r=- \\
0.11 /-0.17 /- \\
0.1\end{array}$ & & & $\begin{array}{l}P=0.19 / 3.0 \times 10^{-2} / \\
0.2\end{array}$ \\
\hline & $\begin{array}{l}\text { GLMM } \\
\text { r distance pairwise accuracydecoder } \\
+ \text { actiontype+animal }\end{array}$ & $\begin{array}{l}N=6, n= \\
11954 \\
\text { observations }\end{array}$ & & & $\begin{array}{l}{[-0.000 .014] /[-0.00} \\
0.00]\end{array}$ & $P=0.19 / 0.93$ \\
\hline $4 \mathrm{E}$ & $\begin{array}{l}\text { Pairwise distance ( } \mu \mathrm{m} \text {; HDA vs ALL / } \\
\text { LDA vs ALL) }\end{array}$ & $\begin{array}{l}N=6 \\
\text { fov }=12 \\
\text { cell }=468\end{array}$ & $\tilde{X}=3.9 / 1.7$ & & $\begin{array}{l}{[-38.552 .2] /[-29.9} \\
33.6]\end{array}$ & $P=1.1 / 1.0$ \\
\hline
\end{tabular}


bioRxiv preprint doi: https://doi.org/10.1101/2020.10.27.357087; this version posted October 27, 2020. The copyright holder for this preprint (which was not certified by peer review) is the author/funder, who has granted bioRxiv a license to display the preprint in perpetuity. It is made available under aCC-BY 4.0 International license.

\section{Supplementary Figures 1-4}


bioRxiv preprint doi: https://doi.org/10.1101/2020.10.27.357087; this version posted October 27, 2020. The copyright holder for this preprint (which was not certified by peer review) is the author/funder, who has granted bioRxiv a license to display the preprint in perpetuity. It is made available under aCC-BY 4.0 International license.

A

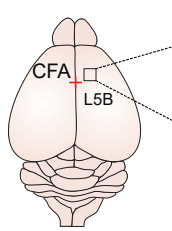

AP: $0.6, \mathrm{ML}: 1.6$

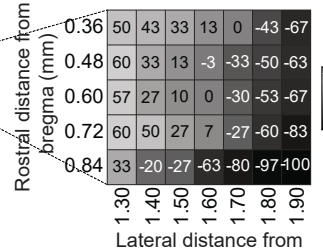

bregma $(\mathrm{mm})$

B
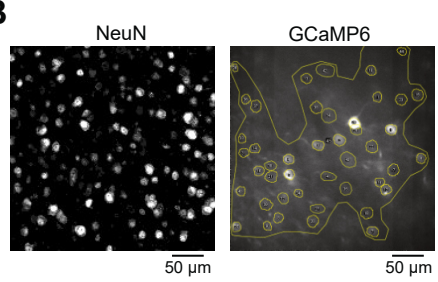

C

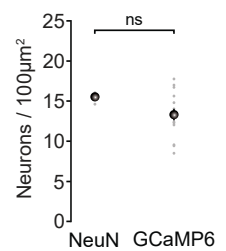

Supplementary Figure 1. Population imaging in layer $5 B$ of mouse primary motor cortex.

(A) Left, schematic showing mapped region of caudal forelimb area (CFA) centred on $0.6 \mathrm{~mm}$ anterior, $1.6 \mathrm{~mm}$ medial of bregma. Red cross denotes bregma; Right, heatmap indicating changes in layer $5 \mathrm{~B}$ depth across a range of cortical coordinates. Values represent the mean depth in $\mu \mathrm{m}$ of the upper boundary of Layer $5 \mathrm{~B}(\mathrm{~N}=3$ mice). (B) $L$ eft, individual neurons within a larger bounded area excluding blood vessels. (C) Average number of NeuN versus $G$ CaMP6s expressing neurons $/ 100 \mu m^{2}$ in layer $5 B$ of $C F A$. Vertical bars depict standard error of the mean and grey dots represent individual slices (NeuN, $n=3$ slices, $N=1$ mouse; GCaMP6s, $n=15$ slices, $N=7$ mice; $t(16)=1.75, P=0.2$, twosample t-test). 
bioRxiv preprint doi: https://doi.org/10.1101/2020.10.27.357087; this version posted October 27, 2020. The copyright holder for this preprint (which was not certified by peer review) is the author/funder, who has granted bioRxiv a license to display the preprint in perpetuity. It is made available under aCC-BY 4.0 International license.

A
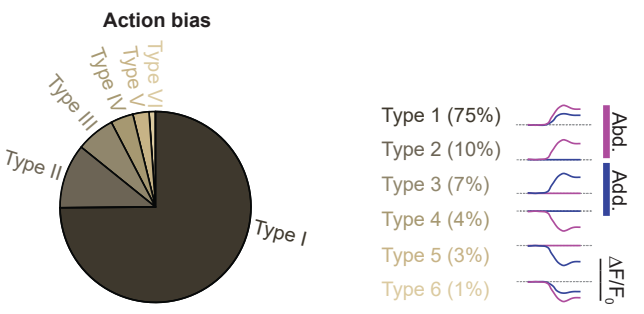

B
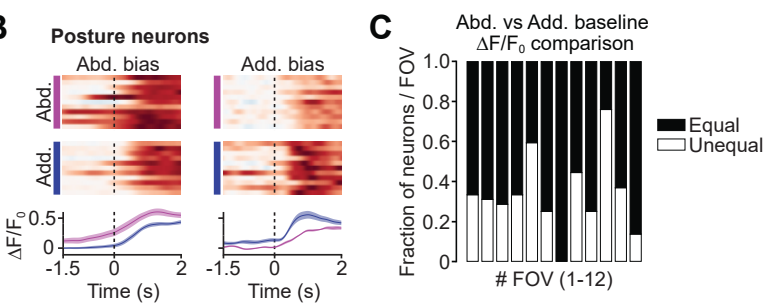

Supplementary Figure 2. Layer 5B neuronal response classification during abduction / adduction trials.

(A) Left, summary of layer 5B neuronal classification; Right, Proportion of cells displaying response types $1-6$ and descriptive $\Delta F / F_{0}$ response profiles. (B) Representative action bias neurons with significant differences in inter-trial baseline $\Delta \mathrm{F} / \mathrm{F}_{0}$; Top, raster showing normalised $\Delta \mathrm{F} / \mathrm{F}_{0}$ across successive abduction or adduction trials; Bottom, $\Delta \mathrm{F} / \mathrm{F}_{0}$ mean area with equal (black: median $=69.5$, IQR $[63.271 .4]$ ) and unequal (white; median $=30.5$, IQR [28.6 36.8]) inter-trial baseline $\Delta F / F 0$ for all 12 imaging fields-of-view ( $=181$ neurons from 12 fields-of-view, $N=6$ mice) 
bioRxiv preprint doi: https://doi.org/10.1101/2020.10.27.357087; this version posted October 27, 2020. The copyright holder for this preprint (which was not certified by peer review) is the author/funder, who has granted bioRxiv a license to display the preprint in perpetuity. It is made available under aCC-BY 4.0 International license.

A

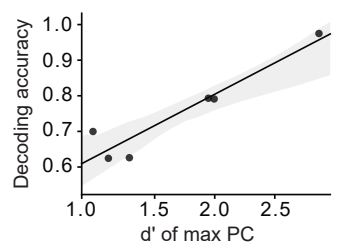

B

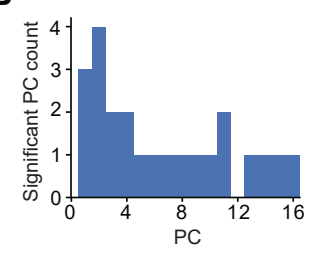

C

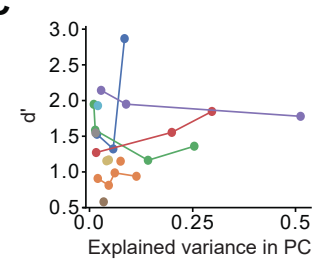

Supplementary Figure 3. A discrimination index for principal components of the population response.

(A) Relationship between population decoding accuracy and the maximum discrimination index ( $\left.d^{\prime}\right)\left(\mathrm{N}=6\right.$ mice, $\left.\mathrm{r}^{2}=0.89, \mathrm{~F}(1,5)=33.6, P=4.3 \times 10^{-3}\right)$. Line denotes linear regression fit, with shaded region representing bootstrapped $95 \% \mathrm{Cl}$. (B) Histogram of significant principal components (PCs) across all 12 fields-of-view (FOVs). (C) Relationship interpretation. Significant d' values are distributed across the full range of PCs and there is no consistent relationship between d' and variance explained. 
bioRxiv preprint doi: https://doi.org/10.1101/2020.10.27.357087; this version posted October 27, 2020. The copyright holder for this preprint (which was not certified by peer review) is the author/funder, who has granted bioRxiv a license to display the preprint in perpetuity. It is made available under aCC-BY 4.0 International license.

A

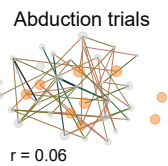

Adduction trials

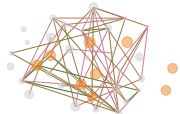

$r=0.10$
B

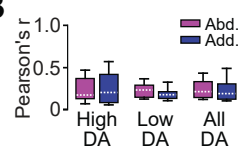

Supplementary Figure 4. Layer 5B neuronal activity correlations during abduction / adduction trials.

(A) Functional networks of neuronal activity from the representative field-of-view (FOV) shown in Figure 4C during abduction and adduction trials. Line colour (light to dark) and width correspond to increasing values of Pearson's $r$. Neurons are plotted as nodes in Euclidean space with colour (HDA - orange; LDA - grey) and size relating to increasing
decoding accuracy ( $n=468$ neurons from $12 \mathrm{FOVs}, \mathrm{N}=6$ mice). (B) Box-and-whisker plots showing the median, interquartile range and range of correlation coefficients across mice for HDA (orange), LDA (grey) and all (brown) neurons during abduction (purple) and adduction (blue) trials. 